\title{
THE RELATION BETWEEN HEART AND JOINT DISEASE INCLUDING “RHEUMATOID HEART DISEASE" AND CHRONIC POST-RHEUMATIC ARTHRITIS (TYPE JACCOUD)
}

BY

\author{
E. G. L. BYWATERS
} From The Department of Medicine, Postgraduate Medical School of London and the Special Unit for Juvenile
Rheumatism at the Canadian Red Cross Memorial Hospital, Taplow

Received October 6, 1949

This study sets out to re-examine the relationship between rheumatic fever and rheumatoid arthritis in the light of a series of cases, studied mainly at the Postgraduate Medical School, on which biopsy or autopsy material is available. It will be concluded that there is every justification for regarding these two as separate diseases.

\section{Historical SURVeY}

Knowledge of the relationship between the disease of the heart and of the joints dates from comparatively recent times.

In 1788 David Pitcairn, in his lectures to the students of St. Bartholomew's, drew attention to the frequent occurrence of heart disease in patients who had been affected with rheumatism. The only record that exists of Pitcairn's original observations is in the second edition (1797) of the Morbid Anatomy written by his friend Matthew Baillie, to whom he passed his practice and the gold-headed cane (Macmichael, 1932). Edward Jenner, independently, in 1789 at a meeting of a Gloucestershire Medical Society at the Fleece Inn, Rodborough, reported An affection of the heart following acute rheumatism, but again this failed to reach print (Keil, 1936). Matthew Baillie himself fully endorsed Pitcairn's opinions, and William Wells, one of Baillie's closest associates, in his classic article on Rheumatism of the Heart (1812) gives the full story and a number of very pertinent cases illustrating this first association of heart and joint disease.

It was left to Jean Bouillaud in 1836 to emphasize this association in his famous law of coincidence: "in the great majority of cases of acute generalized febrile articular rheumatism, there exists a variable degree of rheumatism of the fibrous tissue of the heart. This coincidence is the rule and the non-coincidence the exception."

Between Wells in 1812 and Bouillaud in 1836, Laennec had introduced the stethoscope (1816), and thus it was, through the development of such new techniques, that the succeeding generation of French clinicians were able to establish so firmly the major clinical syndromes. It was not until 30 years later, with the accumulation of a good deal more clinical experience with these new methods, that this "law" was called into question.

In 1869 F. S. Jaccoud gave a clinical demonstration in the Hôpital de la Charité in Paris. The patient was a man of 29 who had had six attacks of articular rheumatism, the first four being severe but short-lived and the last two persistent. The first two attacks subsided completely, leaving neither symptom nor sign. In the third attack the patient developed a severe endocarditis which left him with dyspnœa, œdema of the legs, and well-marked valvular disease. Several months later a fourth attack of rheumatism occurred lasting 4-5 weeks, and once again the joints cleared up completely. 
The heart lesion, however, persisted with the characteristic murmurs of aortic stenosis and insufficiency. Up to now the rheumatism had been of the classical Bouillaud type affecting only the large joints and clearing up rapidly. The fifth attack, however, lasted five months altogether: there was only slight fever this time compared with the severe fever of the previous attacks, and the pyrexia lasted for 2-3 weeks only. The joint pains, however, were severe, affecting the large joints for a very short time and now involving chiefly the hands and feet. After an interval of a few weeks the sixth attack of rheumatism occurred, affecting now the elbows as well, and lasting also five months.

Deformity of the hands developed for the first time in the third month of the fifth attack and was initially correctable, only later becoming permanent. At the demonstration, 7-8 months after the end of the sixth attack, the patient's hands showed muscle atrophy with marked deformity consisting mainly of severe ulnar deviation with slight flexion at the metacarpo-phalangeal $(M C P)$ joints and extensions of the proximal and distal interphalangeal joints of the middle three fingers. The toes were also affected. There were no bony changes clinically and no crepitus: 'Jaccoud explained the deformity as subluxation due to the contracture of the fibrous cords which he demonstrated in the palm. The thumb, he said, was not affected, because the thickened aponeurosis is not attached thereto, nor was the contracture due to muscle change. The case was a rather unusual one but fitted into the category of chronic rheumatism following acute rheumatic fever. The more usual case in this category developed joint changes during convalescence: later the small joints stay painful and ultimately reach the stage of deformity with loss of power.

Homelle, in his article on rheumatism in Jaccoud's dictionary (1882) notes that following a series of attacks of frank rheumatism there persists some trace of inflammation in one or many joints but never to the same degree as with sub-acute and secondary rheumatism. "It is exceptional to see severe forms of arthritis succeeding."

Charcot, in his Clinical lectures on senile and chronic diseases at the Salpétrière, expressed himself thus (New Sydenham Society's translation by Tuke, 1881). "These complications" (endocarditis and pericarditis) " are not exclusively peculiar to this form of the disease. In the first place they are met with pretty frequently in subacute rheumatism in spite of the celebrated law of Professor Bouillaud, a rigorous and tyrannical law, if I may so express myself. ... I I have collected a considerable number of cases in which endocarditis has developed in chronic rheumatism without the disease ever having assumed an acute form." Pericarditis occurred 4 times in 9 autopsies on chronic rheumatism. He quoted two cases with characteristic deformities in which, however, the exact status of the endocarditis remains open to doubt.

Numerous examples of endocarditis in cases of chronic rheumatism were recorded towards the end of the century but it is difficult by modern standards to evaluate them.

Sir Alfred Garrod, in his Treatise on Gout and Rheumatic Gout (1876), records that he had " never met with an instance in which I could trace the occurrence of pericarditis or endocarditis to rheumatoid arthritic disease, however acute the joint affection may have been and I am of the opinion that this absence of cardiac inflammation is one of the best tests for distinguishing this malady from genuine rheumatism." He was aware of Charcot's conclusions but felt " inclined to pause a little as it is possible that the form of the disease in which acute cardiac inflammation has occurred may be rather that of true articular rheumatism of a very subacute character."

His son, A. E. Garrod of St. Bartholomew's, in his Treatise on Rheumatism (1890) records a case of a woman aged 34 who had suffered three attacks of rheumatic fever at 11, 18, and 24 years of age and three fairly severe articular attacks since the age of 24 . Since the last of these she had noticed enlargement of the finger joints typical of rheumatoid arthritis with ulnar deviation. She also showed involvement of other joints and heart disease with a loud apical systolic murmur. A figure shows this post-rheumatic rheumatoid-like arthritis in the hands and a reduceable ulnar deviation without bony change, pain, or crepitus (Fig. 1).

Barjon summarized the possibilities well in 1897. (a) Acute and chronic rheumatism were essentially different diseases. (b) They were two diseases of the same family. (c) Simple coincidence accounted for the occurrence of heart and joint lesions in the same subject. In his series 
of 62 cases, 6 showed mitral valvular disease, 4 aortic, and 3 pericarditis. The cardiopathy was verified in 3 of these, out of a total of 7 necropsies for the series. Two at least of his cases deserve quotation as they closely resemble the case described by Jaccoud.

Case III. Had had rheumatic fever æt. 12 and again æt. 14 the latter attack followed by endocarditis, ulnar deviation and deformity. A third attack occurred at. 18. At 23 years of age he had been free of attacks for 3 years and was at work: he showed mitral stenosis and regurgitation with deformities of the hand (ulnar deviation, limitation, and flexion of the wrist).

Case IV. Had had rheumatic fever at 14,18 , and 26. AEt. 34 he developed swelling and flexion of the $M C P$ joints and fixation of wrists joints with marked mitral regurgitation, still present 8 years later.

Most other references given by the older authorities are of little value, as none of them contain sufficient detail to exclude an acute rheumatoid arthritis with a systolic murmur or a rheumatic fever in older patients with degenerative joint disease, e.g. Spender (1889) talking of " osteo-arthritis as an immediate sequel of rheumatic pyrexia" confines himself solely and perhaps wisely to this remark-"It is of such sufferers that we constantly ask ourselves, especially in our Mineral Water Hospital, 'Is this case going off rheumatoidally?'."

It was not really until well on in the twentieth century, following the discovery by

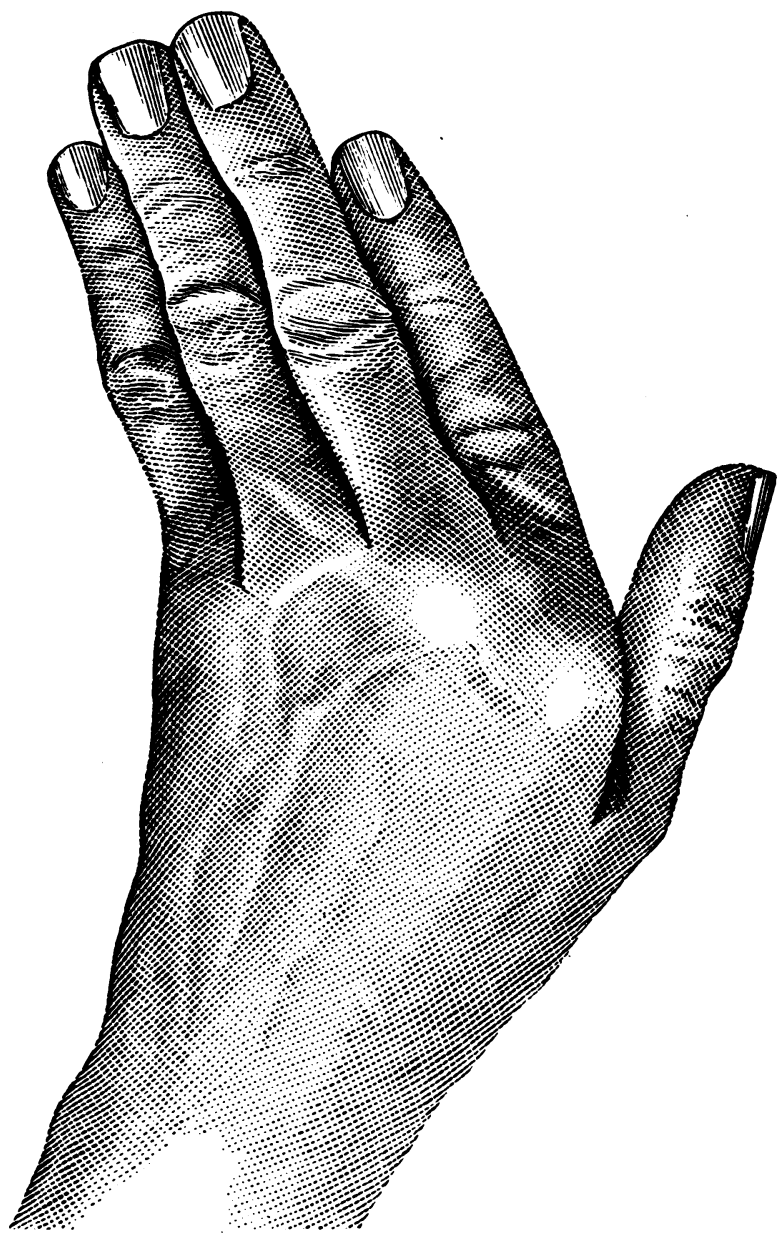

FIG. 1.-Post-rheumatic deformity reproduced from A. E. Garrod, 1890. See text.

Röntgen in 1896 of X-radiation, that adequate diagnostic criteria began to be developed. Since the beginning of the century, very few English-speaking authorities have subscribed to the opinion that rheumatic fever may develop into a chronic articular type of rheumatism. Symes (1905) described and showed photographs of a girl of 16 whose deformities developed out of a previous attack of rheumatic fever at the age of 8 , following which she had pains in the palms and fingers of both hands for many months with the gradual development of flexion deformities. Now there was neither pain, swelling, nor wasting: deformity was present consisting of flexion in the $M C P$ joints and extension of the proximal interphalangeal $(P I P)$ joints which straightened out with very little difficulty (Fig. 2). She had signs of mitral regurgitation and made a complete recovery with hot air baths. Although Bach (1935) stated that the "articula manifestations of rheumatic fever invariably subside completely and leave no sign of chronic joint involvement," he cited two cases with evidence of chronic joint involvement, seen by him among 400 cases of adult rheumatic heart disease attending the National Heart Hospital. Both had mitral stenosis with correctable ulnar deviation and periarticular swellings of the $M C P$ joints without limitation. Fig. 3 shows an enlargement of one of his original X-ray prints, which he has kindly allowed me to see and reproduce. Besides ulnar deviation it shows healed erosions of the third and fifth metacarpal heads together with a slight degree of subluxation, following two attacks of rheumatic fever (see-legend). The original legend reads " Rheu- 
matic capsulitis with a rheumatoid type deformity." To-day most English-speaking modern textbooks make no mention of this type of case.

On the Continent, however, the original conceptions of Jaccoud and Charcot have taken strong root. Grzimek (1932) found 43 per cent of 91 necropsy cases with " genuine arthritis deformans " showed heart valve lesions, whereas 429 control necropsies in the same period showed 18 per cent only. Klinge (1933) recorded 10 autopsies of chronic rheumatoid-like arthritis with or without nodule formation, of whom 8 showed the changes of rheumatic heart disease according to his criteria. While one would hesitate to criticise these cases in retrospect, it appears at least possible that Case 29 had rheumatic synovitis, judged by the illustrations. Case 36 had pericardial adhesions only, Case 38 had senile sclerosis of the aortic valve with probable osteo-arthritis. But even subtracting these, it leaves 5 of the 10 so affected. He thought that the differences between rheumatic fever and rheumatoid arthritis were quantitative rather than qualitative and that the diseases were fundamentally the same. Heart inflammation was correlated, he thought, with the intensity of the attacks, therefore slight in rheumatoid arthritis. He felt that in rheumatic fever the joints showed the same changes as in the early rheumatoid and that in rheumatoid, the viscera, e.g. the heart, showed the same late changes as in rheumatic fever.

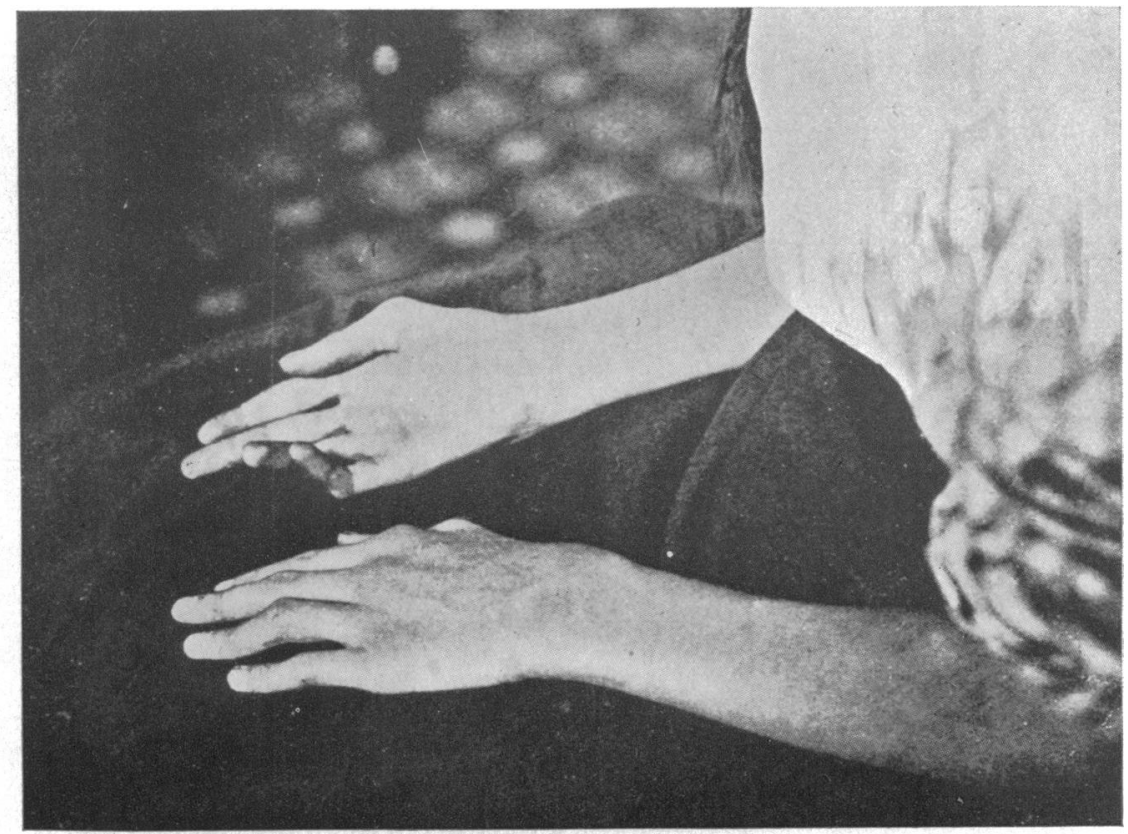

FIG. 2.-Photograph of hands in a case of post-rheumatic joint deformity recorded by Symes, 1905. (For clinicaI history, see text).

Many German-speaking authorities have accepted the implications of this classic work on the pathology of rheumatism (1933). Edstrom of Lund Sweden (1935), noted that a tendency towards chronic arthritis following acute rheumatic infection is more marked in patients who first have rheumatic fever at an advanced age. Out of 694 patients who had been attacked by acute rheumatic fever he found on follow-up that 10 were total invalids on account of chronic arthritis and 14 on account of chronic arthritis together with a heart lesion. Partial invalidism was found in 21 patients on account of chronic arthritis together with heart lesion. Elsewhere he stated that out of these 694 patients, there were 148 with chronic joint diseases of whom 74 also had heart disease. He showed that the number of patients showing the syndrome of chronic arthritis increased by every 


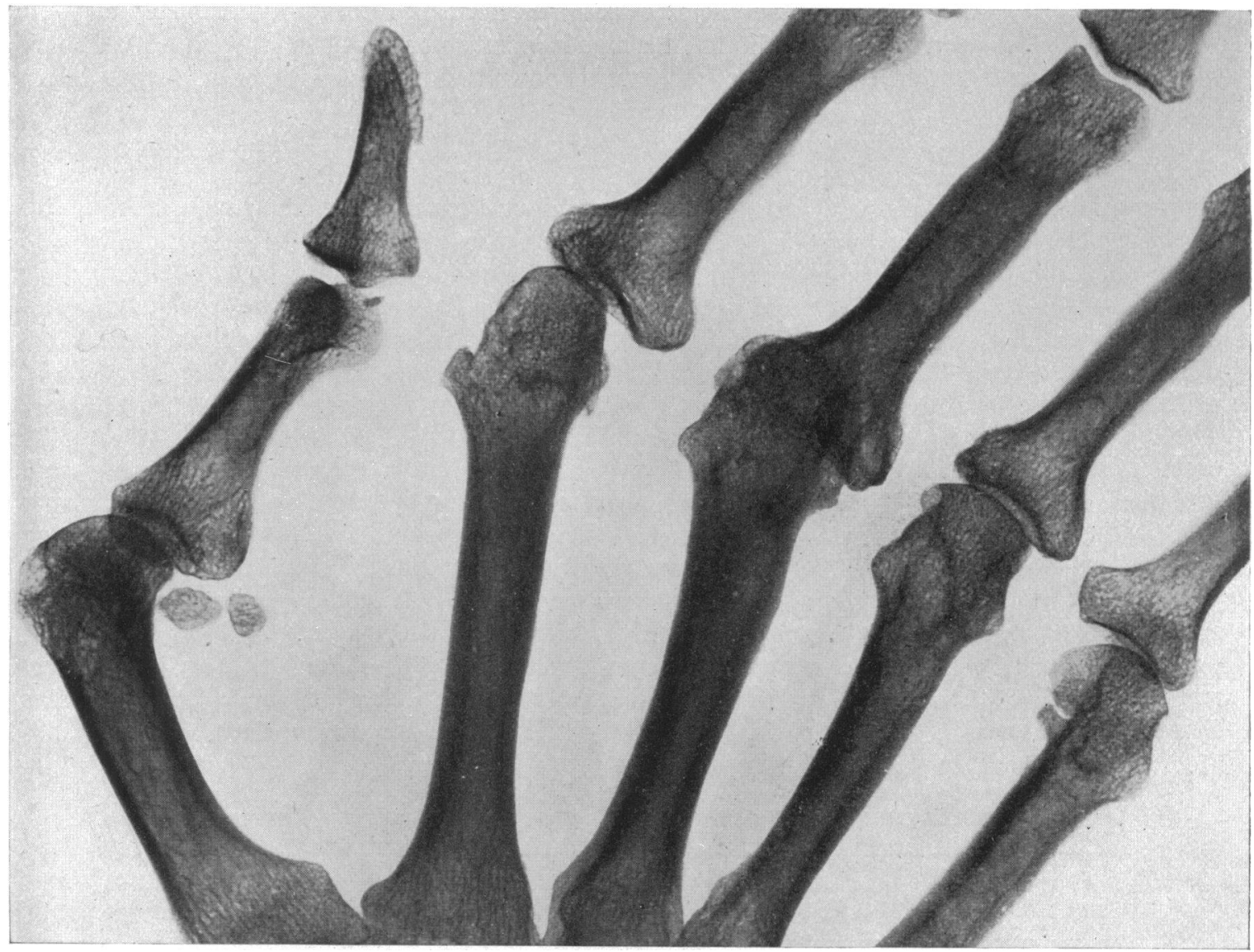

FIG. 3.-Rheumatic capsulitis with rheumatoid-type deformity, reproduced from Bach, 1935. (See text.)

clinical attack of rheumatic fever, so that while only 4 per cent showed chronic arthritis at follow-up after one attack of rheumatic fever, among those who had been affected at least four times, more than 50 per cent showed chronic arthritis.

Freund (1929) in two years with 524 out-patients with joint disease observed 46 with secondary polyarthritis in the above sense; about 40 per cent showed cardiac defects. Fischer in 1933 records 201 cases of whom 65 had valvular defects. Pribram (1902) found clinical evidence of valvular disease in 19 out of 222 cases with chronic rheumatic polyarthritis and heart murmurs in 87.

Unfortunately, however, with the shift of emphasis associated with the rise of German pathology, clinical observation suffered. When English and American technological developments in clinical physiology and biochemistry in their turn took the lead, clinical descriptions became even less adequate, and there are few reports of this type of case in the twentieth century that even with all their adjuvant data will stand the test of time as well as Jaccoud's has done.

While many in the English-speaking world have suspected some relationship between rheumatic fever and rheumatoid arthritis (and a few thought this relationship a very close one, e.g. Dawson, 1935), it was not until 1941 when Bagenstoss and Rosenberg published their remarkably high figures of chronic rheumatic heart disease in autopsies of rheumatoid arthritis $(53 \%$ compared with $5 \%$ in their control series) that general interest in this was re-awakened. Bayles from Boston found 6 cases $(26 \%)$ with gross rheumatic valvular disease in a series of 23 autopsies on rheumatoid arthritis cases; 2 of the remaining 18 had adherent pericardium. Even if we exclude the 5 cases of ankylosing 
spondylitis (of whom 2 had rheumatic heart disease) the incidence does not become appreciably lower $(22 \%)$. However, Bayles thought that this high incidence (compared with his clinical incidence of $5 \%$ ) was due to selection, since 4 out of the 6 were known to have rheumatic heart disease during life.

From Minneapolis, Fingerman and Andrus (1943), found 19 out of 61 autopsy cases of rheumatoid arthritis showed rheumatic heart disease $(31 \%)$. Bennett (1943) found that in 48 autopsied rheumatoid arthritic cases only 7 had rheumatic heart disease for certain (15\%) and 3 rather doubtfully $(6 \%)$ (3 more had pericarditis and 3 died of myocarditis of unknown æatiology). Clark and Bauer surveying what is most probably the same group found pericarditis in 44 per cent, some degree of valvulitis in 20 per cent, and in two cases lesions in the heart similar to rheumatoid subcutaneous nodules, and a peculiar aortitis and aortic valvulitis in one case: in only one case, however, could a certain diagnosis of rheumatic heart disease be made. Smythe (1943) found 5 out of 10 rheumatoid necropsies showed both gross and microscopical lesions of rheumatic heart disease. The highest incidence recorded is that of Young and Schwedel (1944) from New York; of 38 cases, 24 showed valvular disease and 9 pericarditis. They include in their series of 38 rheumatoid autopsies, however, 25 with spinal involvement and only 13 without: the exact status of these is difficult to determine since only 2 are stated to have Marie Strumpell spines and of the 23 remaining with spinal involvement, 14 (i.e. $60 \%$ ) are female and in no case was the spine affected without involvement of limb joints as well. These two facts are contrary to the findings in any other series of spondylitis and although involvement of the spine is known to occur in rheumatoid arthritis proper, particularly during childhood, it is exceedingly rare. The authors also specifically excluded hypertrophic arthritis of the spine. Thus if we exclude cases with spinal involvement, 10 out of 13 cases showed heart disease $\left(77^{\circ}\right)$ although in 3 of them the pericardium was the only structure involved.

TABLE I

Autopsy Incidence of Rheumatic Heart Disease in Rheumatoid Arthritis

\begin{tabular}{|c|c|c|c|c|c|c|c|}
\hline \multicolumn{4}{|c|}{ Series } & Total & $\begin{array}{l}\text { No. with } \\
\text { V.D.H. }\end{array}$ & Percentage & $\begin{array}{c}\text { No. with } \\
\text { pericarditis }\end{array}$ \\
\hline $\begin{array}{l}\text { Charcot. . } \\
\text { Kast .. } \\
\text { Pribram.. } \\
\text { Grzimek } \\
\text { Klinge . . }\end{array}$ & $\begin{array}{l}\cdots \\
\cdots \\
\cdots \\
\cdots\end{array}$ & $\begin{array}{l}\ldots \\
\ldots \\
\ldots \\
\ldots\end{array}$ & $\begin{array}{l}1881 \\
1901 \\
1902 \\
1932 \\
1933\end{array}$ & $\begin{array}{r}9 \\
17 \\
13 \\
91 \\
10\end{array}$ & $\begin{array}{r}0 \\
5 \\
3 \\
47 \\
7\end{array}$ & $\begin{array}{r}0 \\
29 \\
15 \\
42 \\
70\end{array}$ & $\begin{array}{r}4 \\
2 \\
2 \\
- \\
-\end{array}$ \\
\hline $\begin{array}{l}\text { Mayo Clinic } \\
\text { R.B.B. . } \\
\text { Harvard } \\
\text { Minneapolis } \\
\text { Michigan } \\
\text { Montefiore } \\
\text { B.P.G.M.S. }\end{array}$ & $\begin{array}{l}\cdots \\
\cdots \\
\cdots \\
\cdots \\
\cdots \\
\cdots\end{array}$ & $\begin{array}{l}\ldots \\
\ldots \\
\cdots \\
\ldots \\
\cdots \\
\ldots\end{array}$ & $\begin{array}{l}1944 \\
1943 \\
1943 \\
1943 \\
1943 \\
1944 \\
1949\end{array}$ & $\begin{array}{l}30 \\
23 \\
48 \\
61 \\
10 \\
38 \\
31\end{array}$ & $\begin{array}{c}14 \\
6 \\
7-10 \\
19 \\
5 \\
24 \\
7\end{array}$ & $\begin{array}{c}47 \\
26 \\
15-21 \\
31 \\
50 \\
63 \\
23\end{array}$ & $\begin{array}{r}3 \\
2 \\
- \\
- \\
9 \\
2\end{array}$ \\
\hline Total since & .. & .. & 1941 & 241 & 82 & 34 & 16 \\
\hline
\end{tabular}

Although the criteria for the diagnosis of rheumatic heart disease vary slightly from series to series, figures summarized in Table I have depended for the most part upon gross deformities of the valves; evaluation of microscopic stigmata leads on to much more difficult conclusions, e.g. Hall and Anderson (1943) conclude that while only 66 per cent of 100 consecutive autopsied hearts show thickening of the mitral valve, a total of 95 per cent showed stigmata of rheumatic heart disease if microscopical criteria were included. Similarly, according to Barahona and Gorena (1947), of 200 controls, abnormal endocardial vessels were seen in 21 per cent, Aschoff bodies in 7 per cent and rheumatic stigmata without abnormal vessels in 19 per cent, i.e. a total of 40 per cent of normals show signs of rheumatic fever in the past (Table II). 
TABLE II

Incidence of Rheumatic Heart Disease in Control Autopsy Material

\begin{tabular}{|c|c|c|c|c|}
\hline Series & & No. & Gross R.H.D. (\%) & Micro. $(\%)$ \\
\hline $\begin{array}{l}\text { B.P.G.M.S. . } \\
\text { Mayo Clinic .. } \\
\text { Grzimek } \\
\text { Barahona and Gंorena } \\
\text { Hultgren . } \\
\text { Hall and Anderson : }\end{array}$ & $\begin{array}{l}1949 \\
1941 \\
1932 \\
1947 \\
1948 \\
1943\end{array}$ & $\begin{array}{c}1000 \\
\text { All } \\
429 \\
200 \\
100 \\
124\end{array}$ & $\begin{array}{l}6 \cdot 4 \\
5 \\
18 \\
- \\
10\end{array}$ & $\begin{array}{l}- \\
\overline{40} \\
11 \\
90\end{array}$ \\
\hline
\end{tabular}

Koletsky and Karsner conclude from their study of calcific aortic stenosis that all such cases are ultimately rheumatic in origin. It had previously been believed that a high proportion of them were purely degenerative in origin, and Hultgren (1948) concluded that only 11 out of 100 consecutive autopsies blocked by the Gross method, aged 16-86, had rheumatic heart disease, although 46 out of 100 had calcium deposits in the aortic valve. Our own series will be discussed in the light of these findings in the next section.

Finally, a new type of heart disease was recorded in 1941 by Bagenstoss and Rosenberg when they described two cases (in full in 1943) with rheumatoid granulomata in the heart muscle. They were not convinced that this bore no relation to rheumatic fever. These findings have been confirmed in one case published by Raven, Weber, and Price (1948) and in one published by Gruenwald (1948). Thus there seems to be historically three main conclusions:

(1) That rheumatic fever and rheumatoid arthritis are separate diseases (this does not exclude their occasional occurrence in the same person).

(2) That rheumatic fever and rheumatoid arthritis are closely allied, if not the same disease.

(3) That certain types of rheumatic fever may go on to produce a chronic type of rheumatism distinguishable, albeit with difficulty, from rheumatoid arthritis and that certain types of rheumatoid arthritis can produce heart lesions and valvular deformities and pericarditis distinguishable, albeit also with difficulty, from the lesions of rheumatic fever. The conclusions that we shall draw from the data presented in this paper favour the last viewpoint.

\section{The Incidence of Heart Disease in Autopsied Cases of Rheumatoid-like Arthritis}

Between 1935 and 1948, in a series of approximately 4500 autopsies performed in the Department of Pathology (Director-Professor J. H. Dible) at the Postgraduate Medical School, London, 22 cases had what was interpreted by experienced clinicians as rheumatoid arthritis (4 of these 22 occurred prior to 1939 and were not seen personally: 3 of the 4 showed valvular lesions-see later case histories). There were included, in addition, 2 patients with rheumatoid arthritis who died and had autopsies at other hospitals, and 3 with Still's disease, thus making a total of 27 cases; 4 cases of spondylitis ankylopoietica in men came to autopsy during the same period.

In the series of 27 post-mortem cases of rheumatoid-like arthritis, excluding spondylitis ankylopoietica but including Still's disease, no significant heart lesion was found in 14, coronary thrombosis with infarction in 2, and a terminal verrucous endocarditis without any lesion of the underlying valve in one case (Table III). Two cases showed merely slight calcification in the aortic ring at the cusps; both were over 70 years and in the absence of other gross evidence of a rheumatic process, this was considered a degenerative lesion (see later discussion).*

Thus of 27 cases, 19 showed no cardiac lesion relevant to the present study ( $70 \%$ ) (Table III $a$ ). Of the remaining 8 (Table III $b$ ), 3 showed lesions of the heart that we have interpreted as rheumatoid, and 5 showed rheumatic heart disease $(18 \%)$. We suggest later, however, that 1 and possibly 3 of the 5 cases had not rheumatoid arthritis at all, but the chronic post-rheumatic type described

* Unfortunately in these 2 cases and in 3 others out of the 27, no sections of the heart were available for review. 


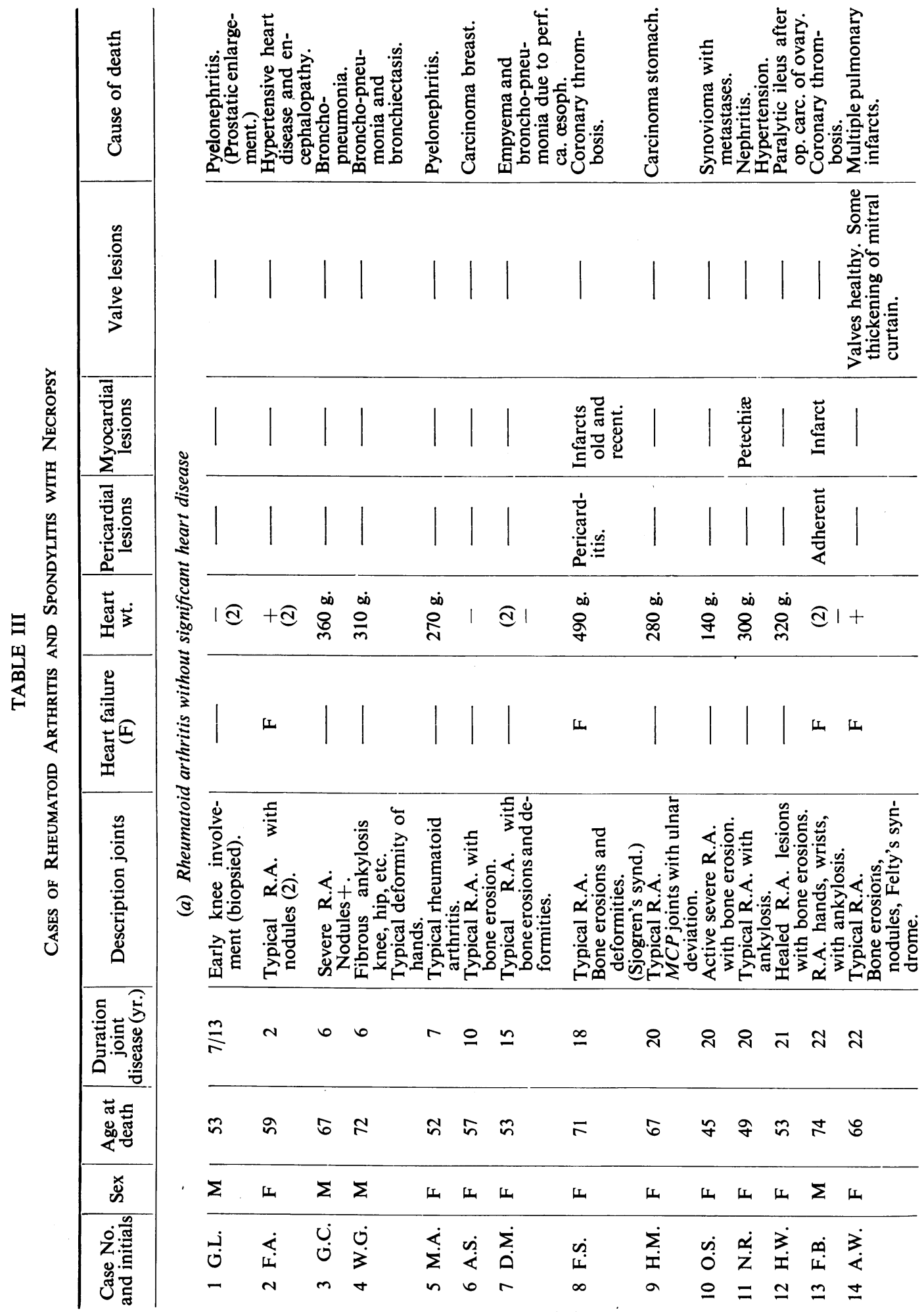

$\underline{\underline{T}}$

T

$\stackrel{\varrho}{7}$

蛋

등

$\frac{\bar{m}}{\bar{D}}$

के

$\vec{\circ}$

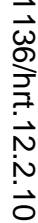

우

궁

ज़

미을

혹

륨

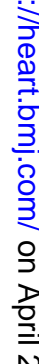

N

N

श्र

을

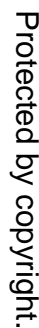




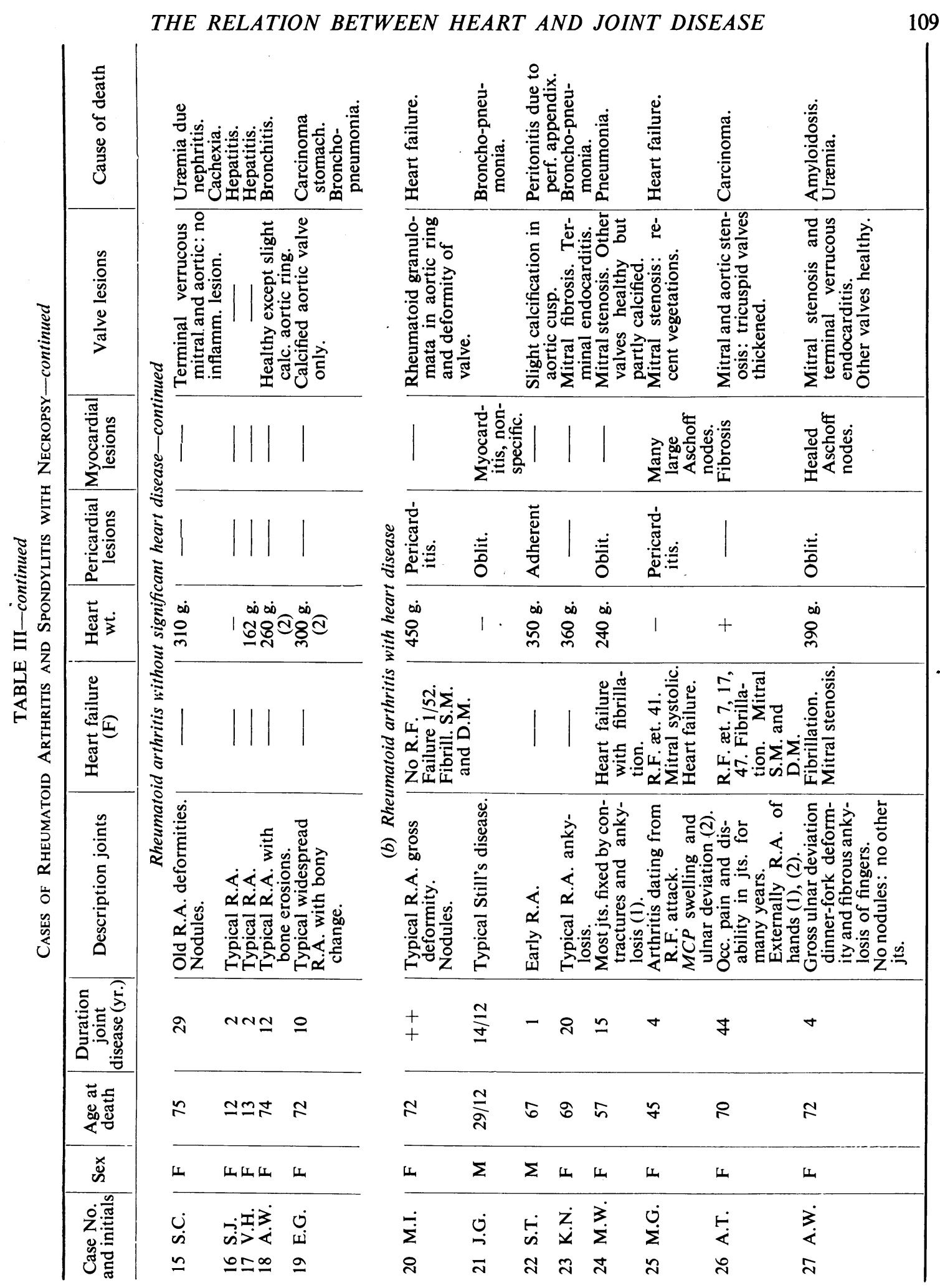




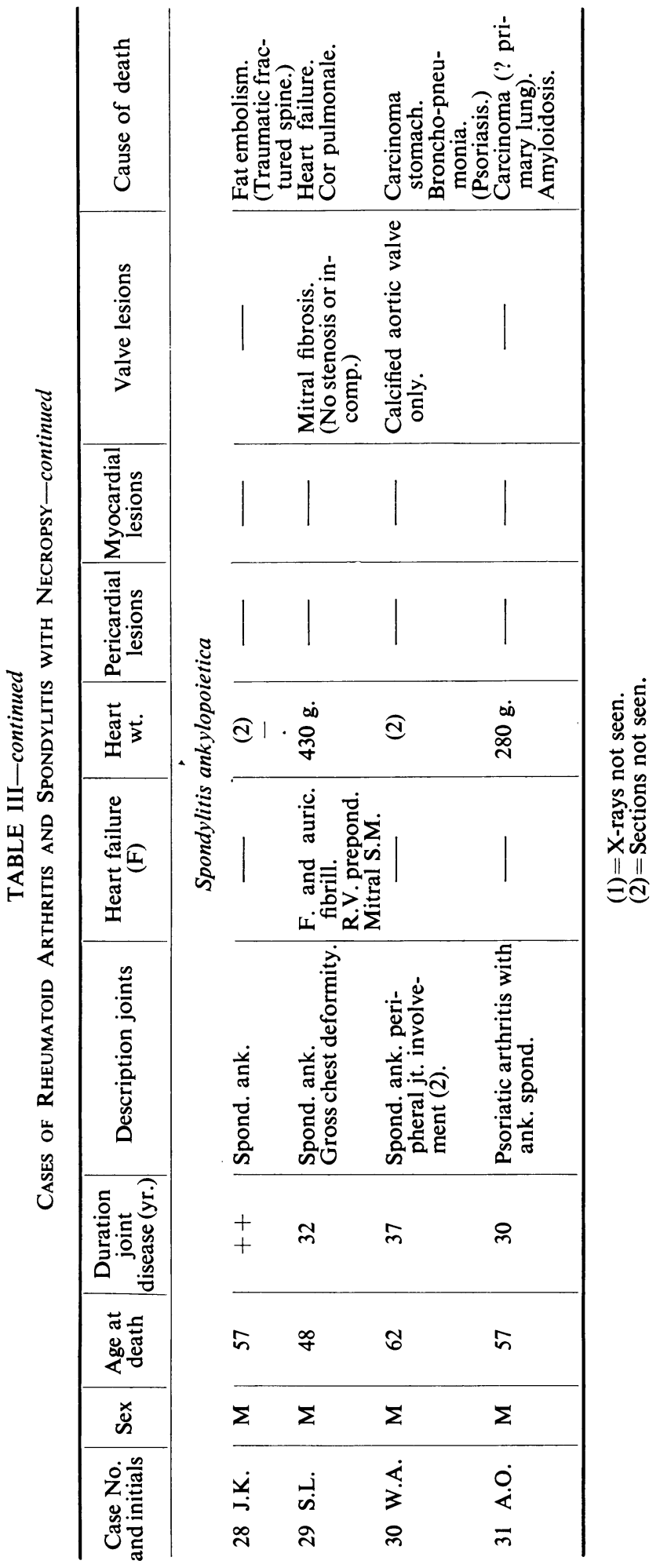


originally by Jaccoud. If this were true it would bring the incidence of rheumatic heart disease complicating rheumatoid arthritis proper by our criteria to 7 per cent and for the age group 41-90, to 8 per cent $(2 / 24)$, a figure that is comparable to the incidence in the control post-mortem material in these decades (including our own-6\%). It is realized that, with these small numbers, it would be incorrect to conclude that rheumatic heart disease was either more or less common in rheumatoid arthritis than in the general population: this figure differs, however, from those published in other post-mortem series (see Table Il) and accords much better with clinical data (Table IV).

TABLE IV

Clinical Incidence of Rheumatic Heart Disease in Rheumatoid Arthritis

\begin{tabular}{|c|c|c|c|c|c|c|c|}
\hline & ries & & & & Year & Total No. & $\begin{array}{l}\text { Percentage } \\
\text { with R.H.D. }\end{array}$ \\
\hline 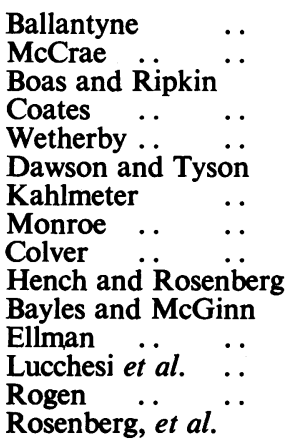 & $\begin{array}{l}\cdots \\
\cdots \\
\cdots \\
\cdots \\
\cdots \\
\cdots \\
\cdots \\
\cdots \\
\cdots \\
\cdots \\
\cdots \\
\cdots \\
\cdots\end{array}$ & $\begin{array}{l}\cdots \\
\cdots \\
\cdots \\
\cdots \\
\cdots \\
\cdots \\
\cdots \\
\cdots \\
\cdots \\
\cdots \\
\cdots\end{array}$ & $\begin{array}{l}\cdots \\
\cdots \\
\cdots \\
\cdots \\
\cdots \\
\cdots \\
\cdots \\
\cdots \\
\cdots \\
\cdots \\
\cdots \\
\cdots\end{array}$ & $\begin{array}{l}\ldots \\
\ldots \\
\ldots \\
\cdots \\
\cdots \\
\cdots \\
\cdots \\
\cdots \\
\cdots \\
\cdots \\
\cdots\end{array}$ & $\begin{array}{l}1898 \\
1915 \\
1924 \\
1931 \\
1932 \\
1933 \\
1934 \\
1936 \\
1937 \\
1941 \\
1943 \\
1944 \\
1947 \\
1947 \\
1949\end{array}$ & $\begin{array}{r}293 \\
500 \\
26 \\
- \\
350 \\
100 \\
85 \\
267 \\
69 \\
\text { All } \\
100 \\
100 \\
50 \\
22 \\
150\end{array}$ & $\begin{array}{c}18 \\
5 \\
11 \\
4 \\
2 \\
7 \\
15^{*} \\
4 \\
1 \\
0 \\
5 \\
8 \\
0 \\
4 \\
3\end{array}$ \\
\hline
\end{tabular}

* 8 per cent of 48 if chronic primary polyarthritis only is considered.

\section{Clinical and Pathological Correlations}

We shall therefore examine in detail the clinical and pathological findings in these 8 cases with combined heart and joint disease and hope to establish, if not quantitatively, at least qualitatively that three groups emerge:

(a) Rheumatoid arthritis with rheumatoid heart lesions

(b) Rheumatic fever with rheumatic heart disease, followed at a later date by rheumatoid arthritis.

(c) Rheumatic fever with rheumatic heart disease complicated by chronic (post-rheumatic) fibrous rheumatism of the Jaccoud type.

Additional cases will be cited from the literature and from our own practice in some of whom biopsy material has been obtained.

\section{(a) Rheumatoid arthritis with rheumatoid heart lesions}

Case 20. M.I., f., age 69 at her first admission. She was deaf and dumb and had been an invalid from arthritis for many years. Examination showed wasting with inelastic skin, and scanty hair. Jugular venous pressure, (J.V.P.) normal. Soft goitre, neck movements limited. Nails ridged and the movements of fingers limited (some muscular wasting). Wrists fixed in flexion. Elbows: bilateral ulnar bursal swellings. Pulse: occasional dropped beat. Blood pressure (B.P.) $150 / 85 \mathrm{~mm}$. Hg. Apex beat $3 \frac{1}{2}$ inches from midline. Occasional extrasystole. No murmurs. Gdema of feet and ankles and healed varicose ulcers of the tibiæ. Right hip and knee fixed in flexion. Toe and ankle movements nil. Hæmoglobin $9.4 \mathrm{~g}$. per cent. No albuminuria. Apyrexial. Discharged on ferrous sulphate after one month.

She was re-admitted three years later and died within a few hours. For the past three years she had been in bed and unable to help herself. One week before admission she started vomiting; this was followed by sweating and cough. She was breathless; systolic and diastolic murmurs were heard at the apex by the admitting officer. J.V.P. to angle of jaw. Apex beat in 6th space: fibrillation. B.P. 140/100. (130/65 in hospital.) Heart sounds were thought to be normal later. Goitre, deformities, wasting present as before. 
Swelling of the knees, feet, and hands. Elbows now limited to $30^{\circ}$ flexion. X-ray of hands: changes typical of rheumatoid arthritis.

Diagnosis. Congestive heart failure with auricular fibrillation and rheumatoid arthritis.

Necropsy.-Marked rheumatoid deformity, collapse of left lung, recent adhesive pericarditis with fibrin exudate. Heart enlarged (450 g.). Right and left ventricles hypertrophied and dilated. Mitral valve normal. Aortic valve cusps grossly thickened and opaque with some fusion of commissures; coronary arteries large and normal. Liver: nutmeg pattern. Kidneys 240 g. and 160 g. with some ischæmic scarring. Spleen firm. Thyroid-goitre.

Microscopically, the joints showed typical rheumatoid changes (Fig. 4). The heart showed rheumatoid granulomata in the aortic ring, partly calcified (Fig. 5 and 6). Olecranal tissue showed subcutaneous nodule formation.

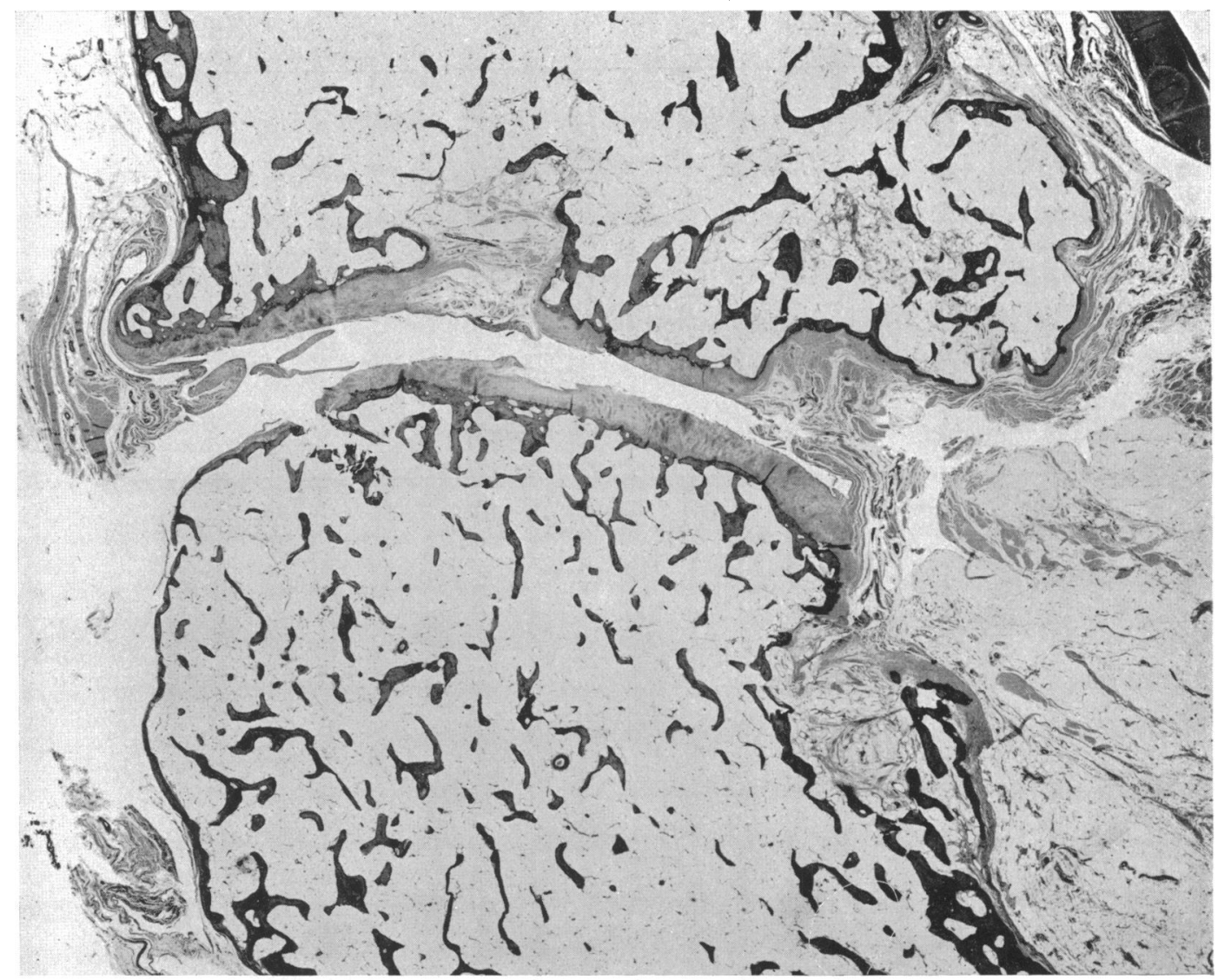

FIG. 4.-Microphotograph $(\times 9)$ of $M C P$ joint (right index) showing diminished joint space, pannus creeping over margins of cartilage, destruction of cartilage at margins and a central defect extending into the bone marrow and bordered by regenerated fibro-cartilage. Case 20.

This is the only case in the series with valvular deformity due to rheumatoid granulomata. She died of congestive failure which had lasted some time judged by the nutmeg liver and had occurred despite her relative immobility. There was no microscopic evidence of healed rheumatic myocarditis, the coronary vessels appeared normal, the goitre did not seem to be toxic, and there was no clinical evidence of hypertension. No Wassermann reaction was performed but there was no specific aortitis. Thus most of the usual causes of failure were absent and we attribute the failure to fibrillation and rheumatoid heart disease. It will be noticed that some considerable fibrosis is apparent in the microphotograph in the neighbourhood of the granulomatous lesion. 


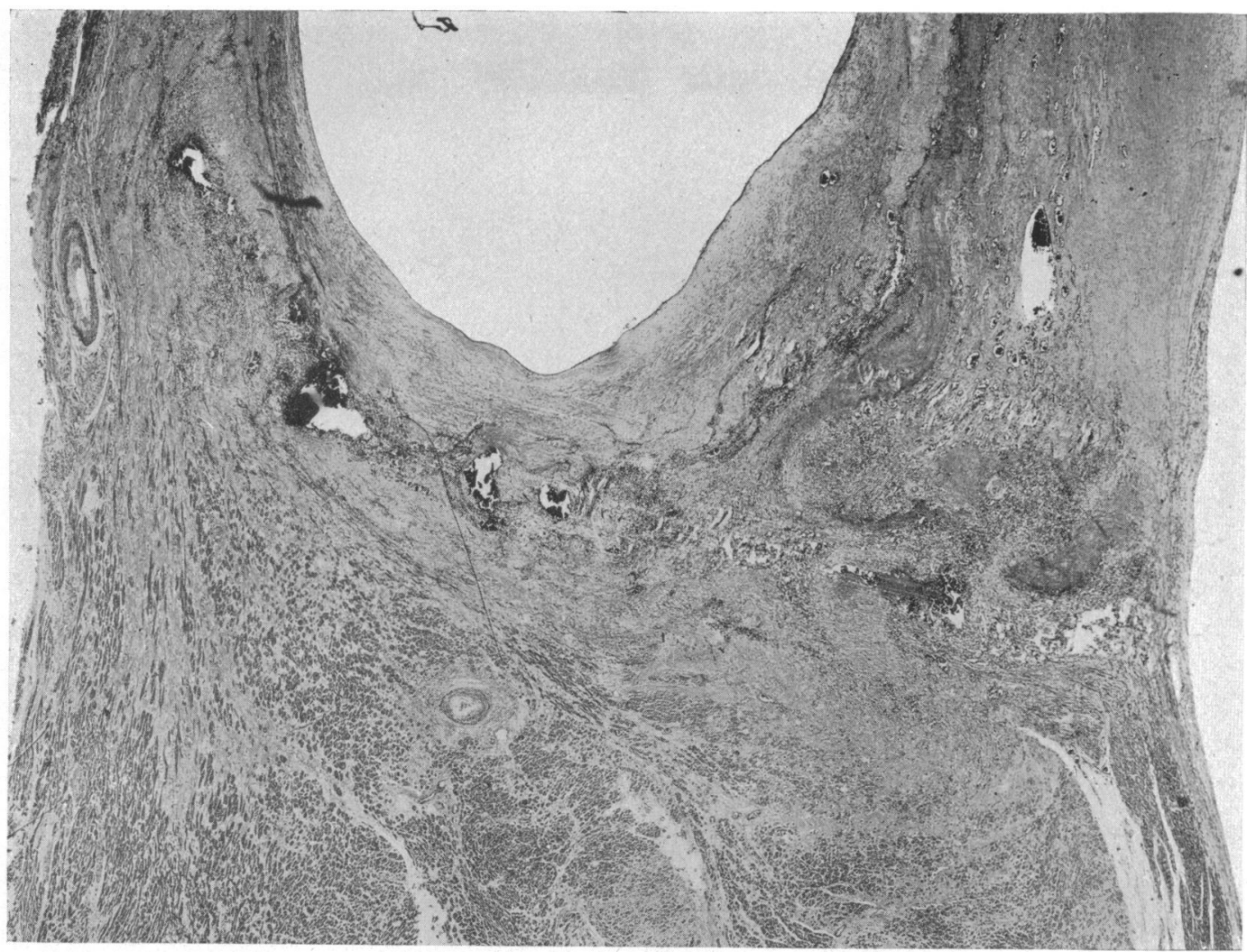

Fig. 5.-Low-power view $(\times 19)$ of aortic ring and base of cusp showing multiple rheumatoid granulomata extending up into the base of the aorta and into the valve as well as throughout the ring area, in places calcified. Note also marked fibrosis of myocardium. Case 20.

Accompanying the aortic valve lesion was a fibrinous pericarditis. Fig. 7 shows how closely it resembles the chronic rheumatoid process in the synovial membrane of the same patient: we believe that this is a specific rheumatoid pericarditis.

Cases similar to this were described first by Bagenstoss and Rosenberg (1941 and 1944). They concluded that the lesions in their two cases could be brought under the classification of rheumatic heart disease and doubted whether they represented a separate disease entity, largely because in one case Aschoff-like structures were present in the myocardium and in the second perivascular scars that have been interpreted as healed Aschoff bodies were present.

The third case was described by Raven, Weber, and Price in 1948, death being due to a cardiac condition characterized pathologically by large rheumatoid granulomata scattered through the heart muscle. Interstitial fibrosis was present but no Aschoff nodes were seen. Mitral stenosis and dilatation of the left auricle was present. There was a history of " rheumatic fever" at the age of 20 and rheumatoid arthritis started 11 years later, progressing to gross deformity and a massive and almost universally distributed crop of rheumatoid nodules. A fourth case has recently been published (Gruenwald, 1948) in a 57-year-old man with rheumatoid arthritis for 6 years. Autopsy showed rheumatoid arthritis of knee joints, destruction of carpal bones, etc., and granulomata characteristic of rheumatoid arthritis in the right atrium, tricuspid valve, pleuræ, and splenic capsule. Clark and Bauer (1948) mention two such cases.

A lesser degree of rheumatoid heart disease consists of pericarditis only. This complication occurs usually below the threshold of clinical consciousness: we have recorded a case elsewhere (Bywaters, 1949) where it was first picked up on a routine electrocardiogram and only later was 


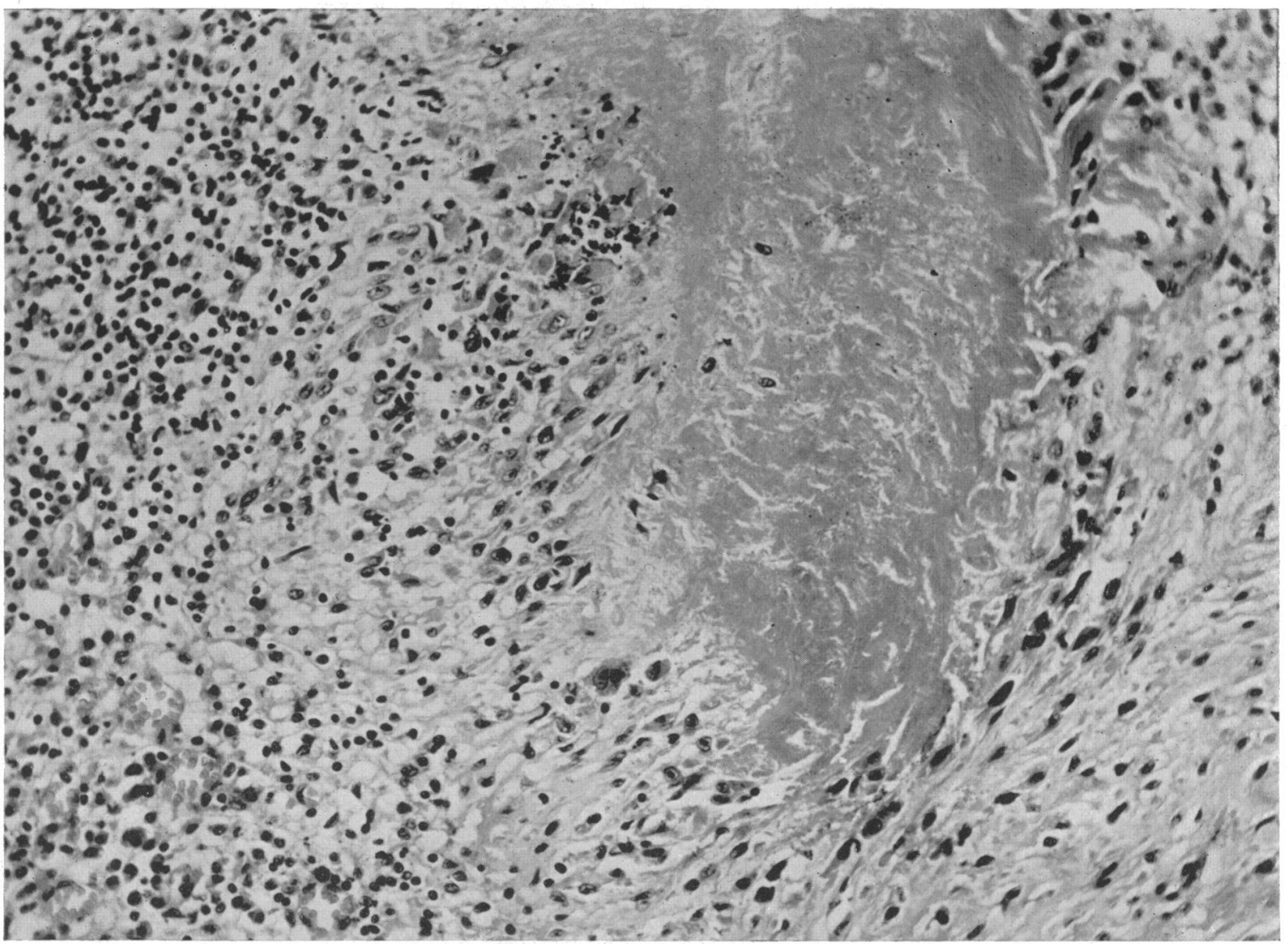

Fig. 6. - High-power view of rheumatoid nodule in aortic ring $(\times 235)$ showing palisade formation, central necrosis and surrounding lymphocyte and plasma cell infiltration. Case 20.

friction heard. Symptoms were minimal. Usually pericarditis is only diagnosed post mortem where the visceral and parietal layers are seen to be adherent the one to the other, sometimes with a few inflammatory cellular collections-old fibrin and blood vessels left in the scar.

In children, however, pericarditis is not only more frequent (it was present in the 3 autopsies originally described by Still) but also more widely known to occur and therefore more frequently observed during life. In our Taplow series of 20 cases of Still's disease (or rheumatoid arthritis starting before the age of 16) pericarditis has been detected clinically thrice. In the autopsied series one of the three cases of Still's disease showed pericardial obliteration as well as pleurisy and perisplenitis, and will be detailed in full elsewhere. Briefly, the boy (Case 21) was $2 \frac{1}{2}$ years old at death and had had arthritis for one year. Clinical evidence of pericarditis was sought but not found: the only other heart lesion was a widespread focal interstitial (non-rheumatic) myocarditis.

In the 24 adult cases of this series with chronic rheumatoid-like arthritis on whom necropsies were performed, adherent pericardium was noted seven times, in 2 cases associated with myocardial infarct and in 3 with rheumatic heart disease, leaving only 2 in whom it could possibly be attributed solely to the rheumatoid process. In the case already detailed with aortic valve deformity due to rheumatoid heart disease, the pericarditis closely resembled the granulomatous lesion in the synovial membrane (Fig. 7). In the other the rheumatoid process was of about one year's duration:

Case 22. S.T., m., æt. 68 at death, had had recurrent painful swellings of left knee since a football accident æt. 37. When admitted to hospital, æt. 60, for dyspepsia no abnormality found. 
Æt. 66, developed painful swelling of shoulders, fingers, wrists, knees, and ankles lasting one month. A year later, left knee swollen, and then pain in right hip, left ankle, shoulders, wrists, and hands which became swollen.

Examination showed painful limitation of movement, swelling of left 2 nd and 3rd $M C P$ joints with weakness and atrophic skin. Fluid in knee joint. Hæmoglobin 10.8 g. Blood sedimentation rate (B.S.R.) 65 and $85 \mathrm{~mm}$./hr. Heart: no abnormality. No nodules. X-rays: left basal fibrosis and chronic arthritic changes in the right acromio-clavicular joint: no changes in hands.

Ft. 68, stiff neck for three months and stiffness and swelling of the hands. B.S.R. $18 \mathrm{~mm}$./ hr. Typical deformities of rheumatoid arthritis in the hands; treated by diathermy. Four weeks later, admitted with a perforated appendix, and died after 4 days. Heart sounds normal. B.P. 140/85.

Necropsy showed broncho-pneumonia and peritonitis due to perforated appendix. The heart showed old adhesive pericarditis: there was slight calcification in the aortic cusp and calcification of coronary vessels. All the valves appeared normal. Rheumatoid changes were seen in the 2nd and 3rd fingers and in the right shoulder grossly and histologically. X-rays showed bone erosions.

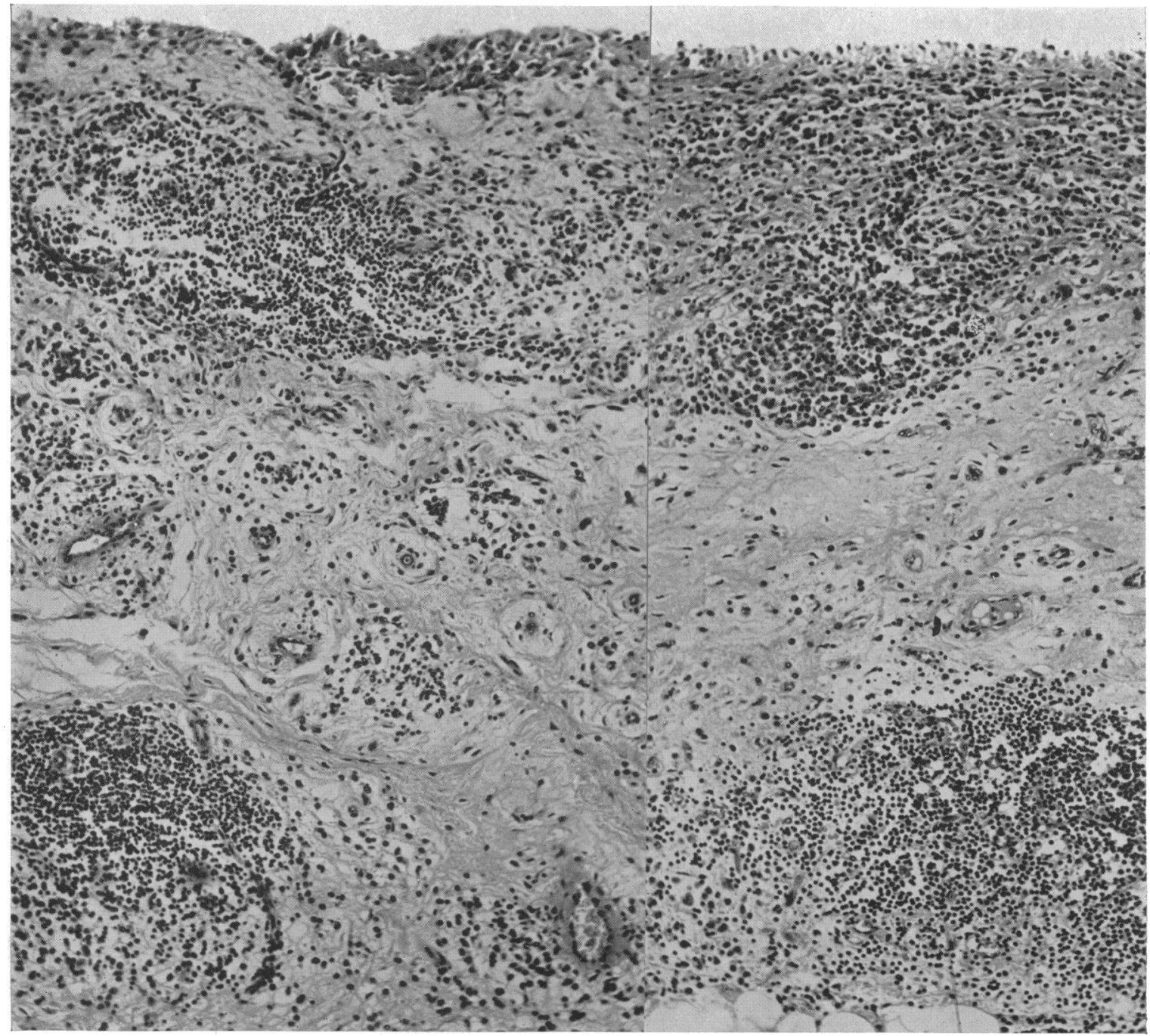

Fig. 7.-Microphotographs of synovial membrane of knee (left), pericardium (right). Both $\times 120$. Note marked similarity, with hyperplasia and fibrin incorporation of lining membrane, diffuse plasma and lymphocyte infiltration deeper. Case 20. 
(b) Rheumatic fever complicated by rheumatic heart disease with later development of rheumatoid arthritis

Case 23. K.N., f., æt. 69 at death, had had rheumatoid arthritis for 20 years, affecting her hands and legs and had been unable to walk for 10 years.

Examination. Systolic murmur at apex. Fusiform swelling of fingers. Knees and ankles fixed in flexion. Death was due to confluent broncho-pneumonia.

Necropsy. The heart (360 g.) showed terminal endocarditis on the mitral valves. Microscopically these were thickened and showed marked fibrosis and distortion, with increased vascularity. The joints showed typical active rheumatoid arthritis microscopically with destruction of cartilage and ankylosis.

Case 4: M.W., f., æt. 57; died within 24 hours of admission: lobar pneumonia of 4 days duration. Crippling rheumatoid arthritis since 42 years of age.

Examination. There were contractures of both upper and lower extremities. Hands and feet were markedly deformed with an old rheumatoid arthritis. No X-ray seen.

Necropsy. Most joints were fixed by contractures and ankylosis. Microscopically the synovial membrane was typical of rheumatoid arthritis. The pleural cavities were obliterated and there was apical scarring and lobar pneumonia. The pericardium was completely obliterated. The mitral valves were short, thick, fibrosed, and partially calcified, showing stenosis. Other valves were healthy. No myocardial lesions were seen microscopically. The spleen showed sugar-jcing.

Although neither of these gives a history of rheumatic fever, the heart lesions were typical of rheumatic heart disease and the joint lesions of rheumatoid arthritis. Three other cases also had rheumatic heart disease, but because of atypical features in the joint disease they will be discussed in the next section as doubtful (Case 27), possible (Case 26), and probable examples (Case 25) of postrheumatic joint disease rather than of rheumatoid arthritis.

If there were no special relationship between rheumatoid arthritis and rheumatic fever, rheumatic heart disease should occur in cases of rheumatoid arthritis in the same proportion as in the general population-affecting in this age group about 5-10 per cent according to gross findings at autopsy. If finer pathological criteria are adopted it is possible to assert that 90 per cent of people have had and bear scars of rheumatic heart disease, although only 10 per cent (12 out of 124) show valvular lesions in the commonly accepted sense of the term (Hall and Anderson, 1943).

It is perhaps surprising in view of the frequency of Group A hæmolytic streptococcal infections and the occurrence in 20 per cent of such infections of a post-streptococcic state that is indistinguishable from mild forms of rheumatic fever (Rantz, Boisvert, and Spink, 1947) that so small a proportion are affected clinically. Clinically, rheumatic heart disease occurs in a relatively small number of cases of rheumatoid arthritis (e.g. 2\% Wetherby, 1932, 8\% Ellman, 1944, 0\% Lucchesi et al., 1947, 5\% Rogen, 1947, 7\% Dawson, 1933, 0\% Hench and Rosenberg, 1941, 5\% Bayles and McGinn, 1943) (see Table IV). It should occur in an even smaller proportion if cases with a history of rheumatic fever are excluded (e.g. 5\% Fischman and Gwynne, 1948). A much higher proportion of heart disease in rheumatoid arthritis $(30 \%)$ is claimed by Feiring (1945), but it seems highly probable that the criteria adopted and the short period of observation-a few months only, have allowed of the inclusion of cases with subacute rheumatism and rheumatic fever.

In a well-documented case the temporal relationship between the two coincident diseases is quite clear.

W.H., f., æt. 31. Rheumatic fever, when aged 6 and 28. Sixteen months before entry, swelling, stiffness and pain in third right $P I P$ joint; later $M C P$ joints, knees, and ankles affected.

Examination. Mitral stenosis, aortic regurgitation, swelling of $M C P$ and $P I P$ joints with weakness and wasting (Fig. 8), involving also right wrist, left knee, left ankle, and left $M T P$ joints. On radiography, osteoporosis, subchondral rarefaction and diminished joint space in wrist and finger joints. B.S.R. 103, falling to $90 \mathrm{~mm}$./hr. 6 weeks later. Synovial fluid of rheumatoid type (low sugar, high protein). Followup when æt. 34 showed chronic arthritis wrists, ankles, and fingers and radiologically erosion of $P I P$ joints. B.S.R. has remained between 23 and 38 .

(c) Rheumatic heart disease with chronic fibrous rheumatism (Type Jaccoud).

During recovery from rheumatic fever cases are not infrequently seen which present during the subsidence of rheumatic activity a periarticular swelling of joints, best marked in the $M C P$ joints, 


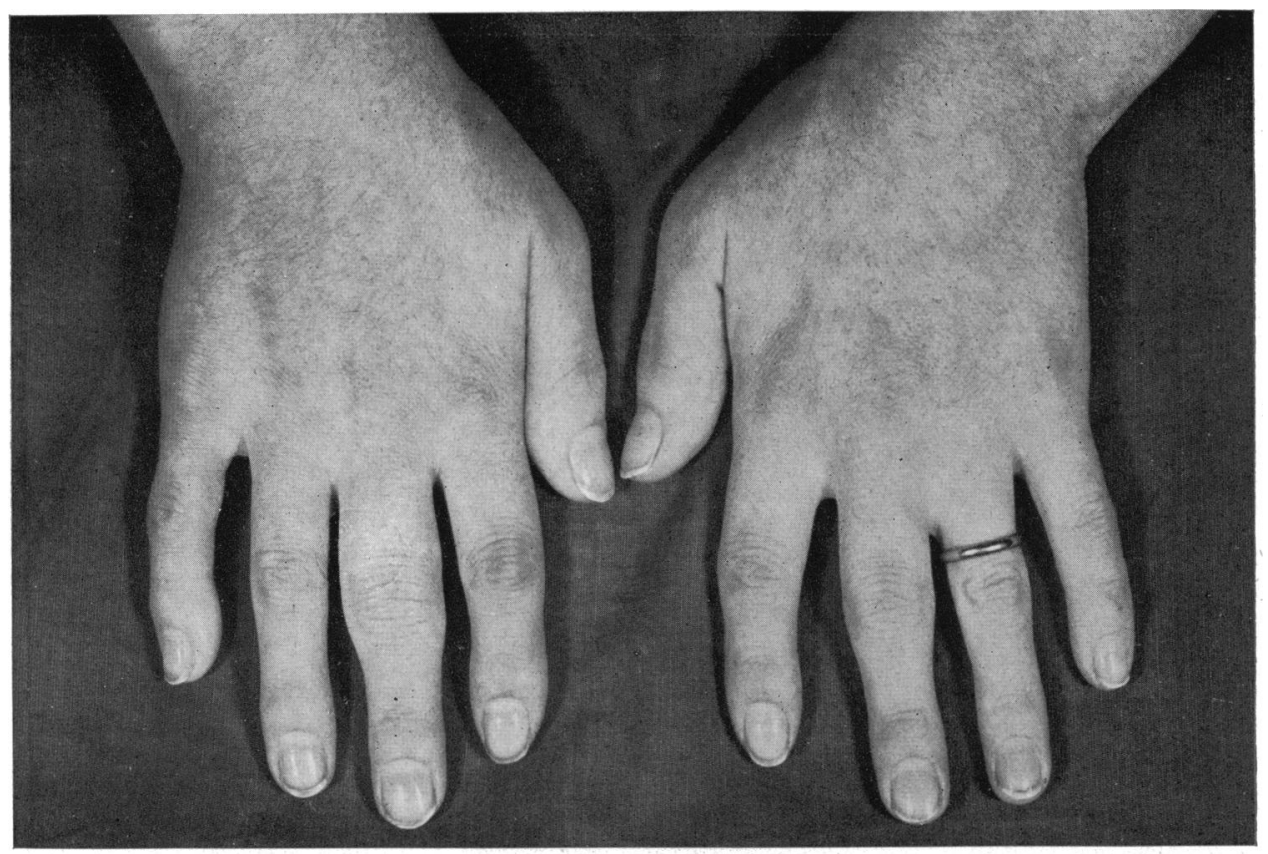

sometimes in the PIP joints. This is usually associated with marked nodule formation, as in the following case.

E.G., f. First attack of rheumatic fever at the age of 15. Six months later she developed a second attack with arthritis, chorea, marginate rash, and pericarditis. The joints subsided rapidly on salicylates. As the B.S.R. came down from 85 on entry to 45 , 11 days later, spindling appeared in the PIP joints due to prenodular thickening and nodules (biopsied). These lasted for a period of four months although the B.S.R. fell to normal (11 mm./hr.) after 35 days. The accompanying figure shows the simulation of rheumatoid arthritis (Fig. 9). At follow-up two years later, no residual swelling was seen.

In general these cases subside completely even when there have been changes even more marked than the preceding case. These severe types seem to be more common in (but not confined to) adults.

R.W., m., æt. 44, admitted with a rash and painful joints, gave a history of pain and swelling in his joints when 26, lasting 17 weeks. Tonsillitis occurred one month before present admission and painful stiffness in his joints nine days before.

Examination showed some effusion with redness of right knee and both feet; soft apical systolic murmur and widespread circinate but slightly raised (urticarial) rash. Sedimentation rate $116 \mathrm{~mm}$./hr. P-R interval 0.22-0.24 seconds with electrocardiographic evidence of pericarditis and ventricular extrasystoles. Fever and arthritis responded to salicylates. Nodules (biopsied) developed on olecranon and knuckles and B.S.R. fell slowly to 33 by the 150th day. The hands were still rather closely stiff, the $M C P$ joints and wrists slightly limited with periarticular thickening. There was also wasting of the interossei. X-rays showed marked rarefaction, estimated quantitatively by a previously described method (Bywaters, 1948) and shown in the accompanying charts (Fig. 10A and 10B). Seen one year and again four years from onset, patient had mitral stenosis, no joint involvement clinically or radiologically, and a B.S.R. of $5 \mathrm{~mm}$./hr.

These cases probably represent the early stages (the "forme fruste") of the Jaccoud syndrome; sometimes, however, more chronic changes occur as in the following case.

J.G., f., æt. 12, developing her first attack of polyarthritis and chorea two weeks before admission. Following salicylate therapy, joint systems subsided leaving her with diastolic murmurs at apex and base. 


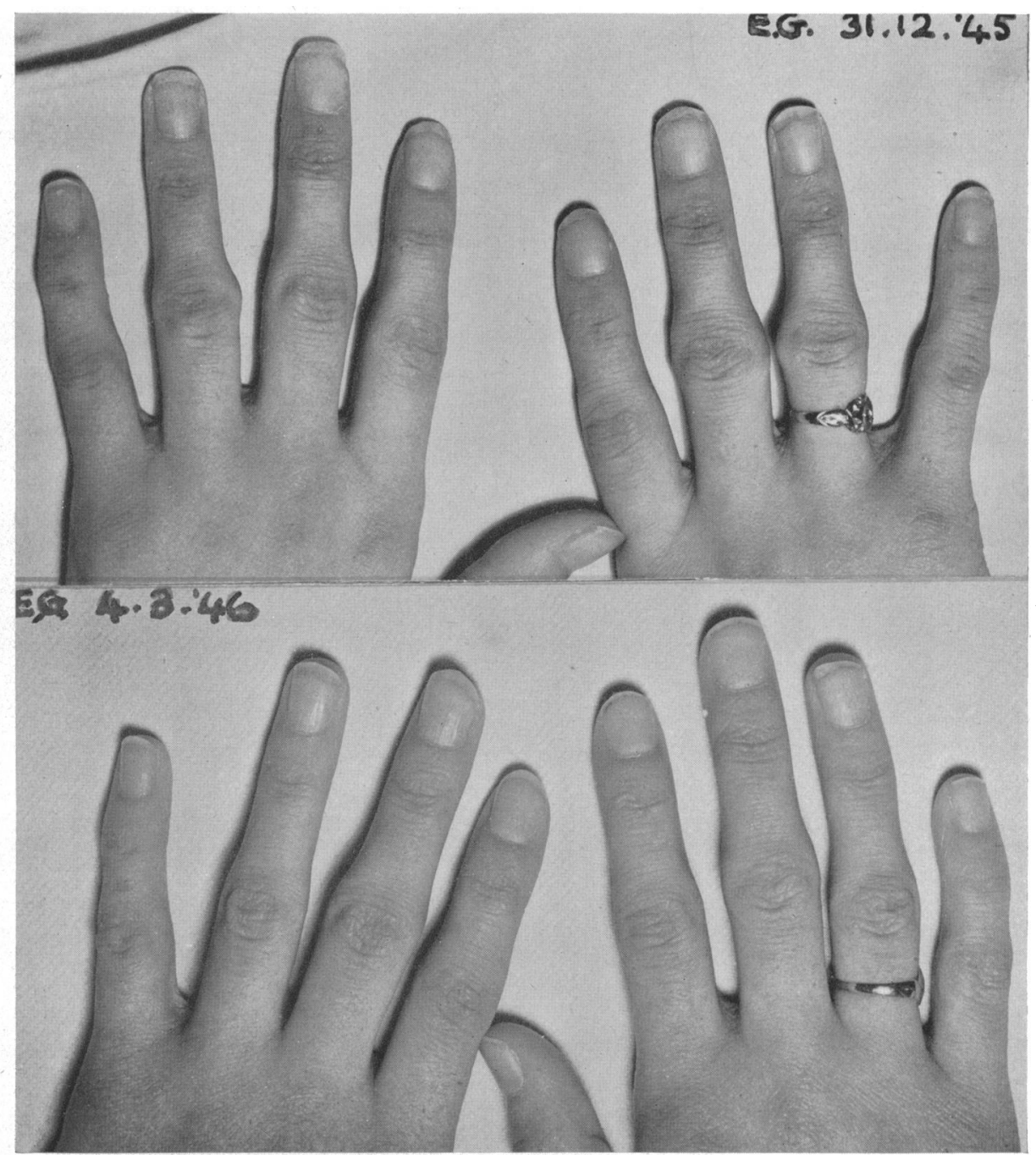

FIG. 9.-Hands showing spindling due to periarticular nodule-like plaques with later resorption. Case E.G.

After ten weeks, nodules and periarticular swelling developed, particularly $M C P 2$ and 3 left. She ran a prolonged active course lasting seven months with a B.S.R. initially $83 \mathrm{~mm}$./hr. falling gradually to $40 \mathrm{by}$ 20 weeks and 14 by. 30 weeks from admission. At eleven months the $M C P$ joints showed marked periarticular swelling with slight degree of fixed flexion and correctable ulnar deviation. There was some interosseous wasting (Fig. 11). X-rays showed no bony change. Two months later (i.e., when she had been relatively inactive, except for a recurrence of chorea for six months with an average weekly B.S.R. over this time of $13 \mathrm{~mm}$./hr., a biopsy of the still swollen right index $M C P$ joint showed normal synovial membrane and marked basophilia of interfibrillar ground substance of the capsule (Fig. 12).

Recently, however, a case was observed through the kindness of Dr. Coghill of the West Middlesex Hospital, London, of a degree thought to be previously unrecorded during life, which we think is of similar status to the cases with chronic arthritic changes of advanced type such as Klinge has examined post-mortem.

O.L., f., æt. 25 years. In 1940 at the age of 17, she developed a first attack of rheumatic fever with polyarthritis followed by chorea. Her left wrist and both knees were swollen and painful but not her finger 


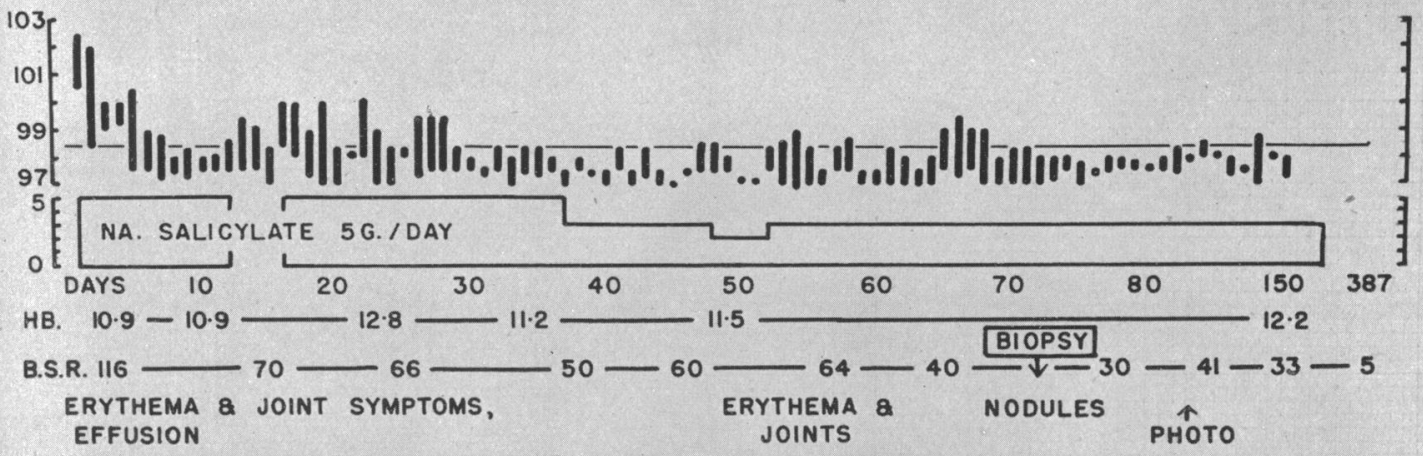

E.C. G.

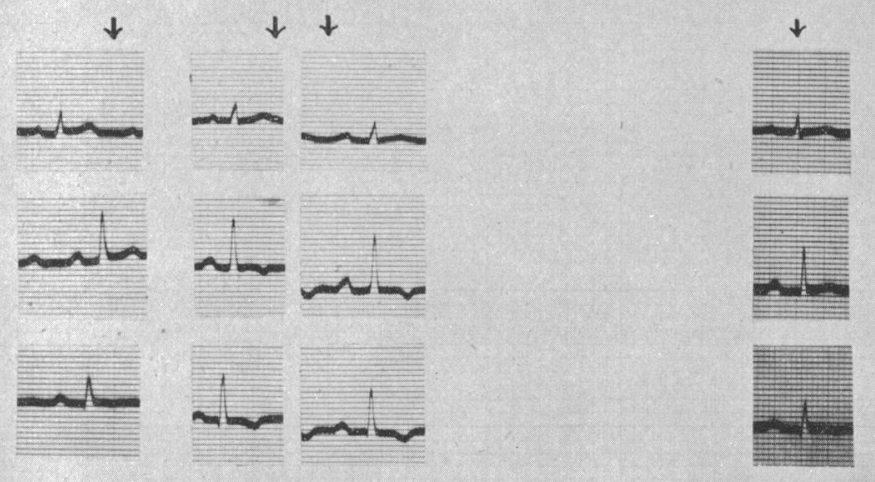

FIG. 10 A.-Chart of case showing prolonged rheumatic fever joint involvement. Case R.W.

Fig. 10 B.-Osteoporosis developing rapidly in hands (same case) of prolonged rheumatic fever joint disability. During period of decalcification sedimentation rate was raised. Follow-up shows return to normal bone opacity. Case R.W.
R.W., M. AET. 44 RHEUMATIC FEVER.

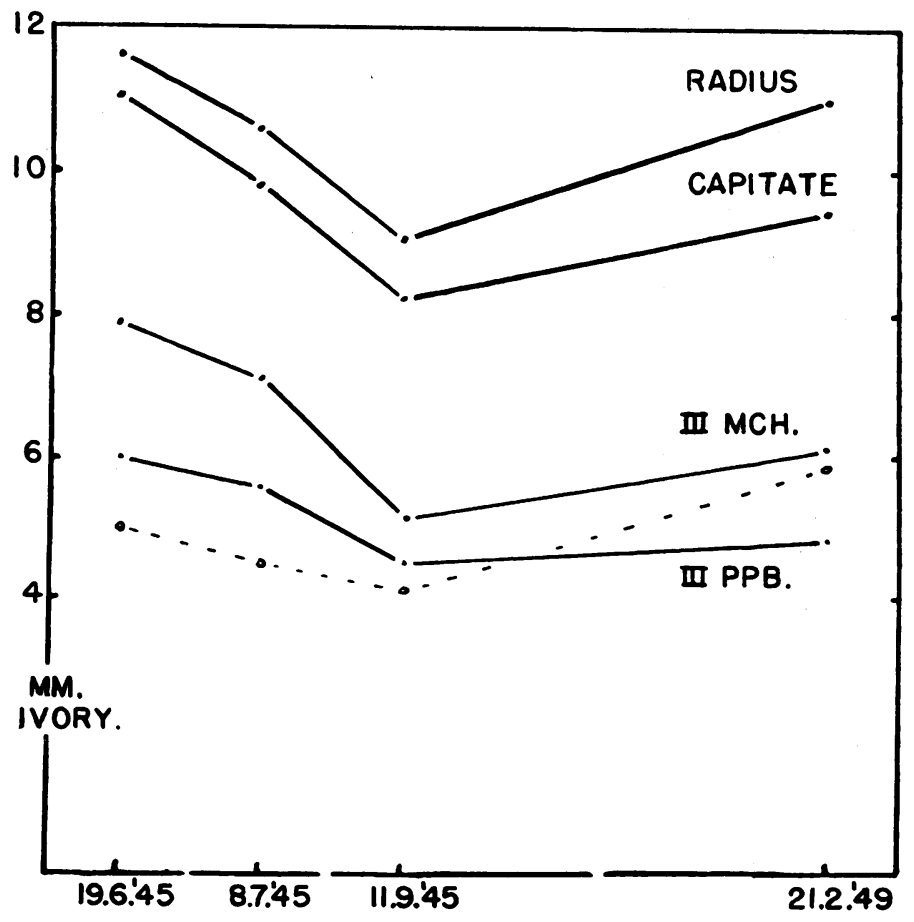




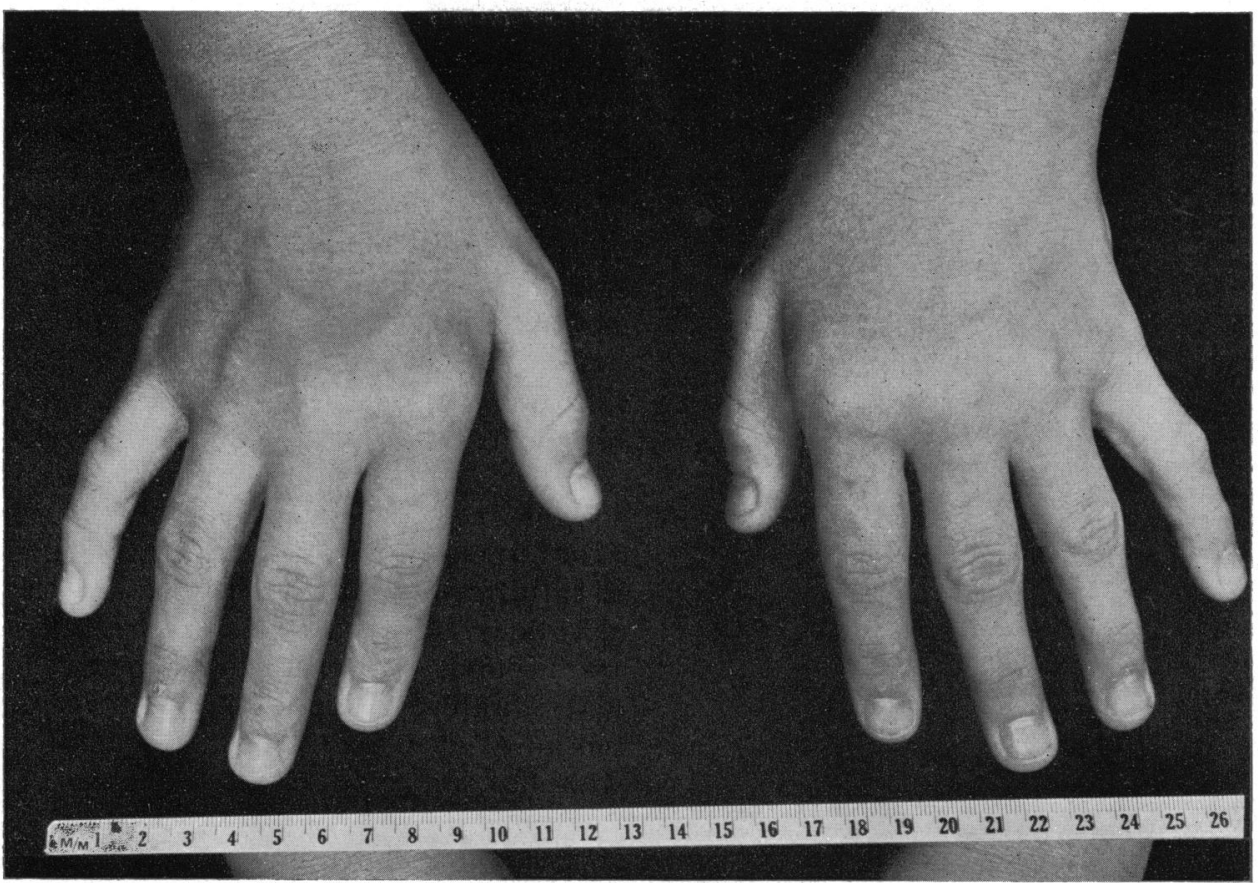

Fig. 11.-Hands showing flexion deformity at $M C P$ joints and slight ulnar deviation with periarticular swelling. Case J.G.

oints. She had nodules on her elbows. On discharge a month later, some aching of her fingers was noted for some months and she noticed that the knuckles were red and swollen. The chorea returned for a short time in 1941 but disappeared without medical treatment. In 1943 she noticed a disability in her hands; she was unable to hold the palms of the hands closely together (as in the attitude of praying) (Fig. 13), and the fingers particularly on the ulnar side began to move outwards. This ulnar deviation could be corrected voluntarily (Fig. 14). There has, however, been no pain in the joints or any rheumatism for the last five years and the patient has felt in good health. She has continued with her work as a medical secretary and typist and has no complaint of the joints. She was admitted because of recently noticed scotomata. Examination showed a block of the upper ciliary retinal artery with edema of ciliary retina (Mr. P. H. N. Matthews). There was evidence of mitral stenosis and aortic incompetence (pre-systolic and loud systolic murmur at the apex and early diastolic basal murmur). Screening showed slight enlargement of the left auricle and the oesophagus displaced slightly backward in the first oblique position. B.P. 115/75. No pyrexia, no petechiæ, no nodules. Blood cultures negative. No urinary abnormality. Hæmoglobin 100 per cent (Haldane). W.B.C. 8400 . Spleen not palpable. B.S.R. $4 \mathrm{~mm}$./hr. The hands both showed ulnar deviation (Fig. 14) more on the right side than on the left, particularly involving the 4th and 5th phalanges, together with gross swelling of the $M C P$ joints $(2,3,5$ right and $1,2,3,5$ left and $3 P I P$ right). There was no limitation of movement except incomplete extension, but some interosseous wasting and contracture of palmar fascia. Gross creaking and some crepitus was heard on extension against slight resistance of the flexor tendons of the 2nd and 5th right fingers. The ulnar deviation could be voluntarily corrected and thus maintained, but on relaxation the fingers assumed the deviated position.

$X$-rays showed ulnar deviation and bony erosion involving the $M C P$ heads of the right 3 and 5 (doubtful right 4). There was some evidence of previous inflammatory change affecting the ulnar styloid of both sides and sharpening of the bones adjoining the radio-ulnar joint right (Fig. 15). Biopsy (Fig. 16) showed normal synovial membrane and basophil fibrosis with pyknotic remnants between the bundles of collagen in the capsular tissue.

It is thought that these changes were due to prolonged rheumatic activity and that bone erosions were due to rheumatic fever. It is not thought that they represent rheumatoid arthritis. Valuable evidence against this is given by the lack of symptoms, the biopsy, and the normal B.S.R. 


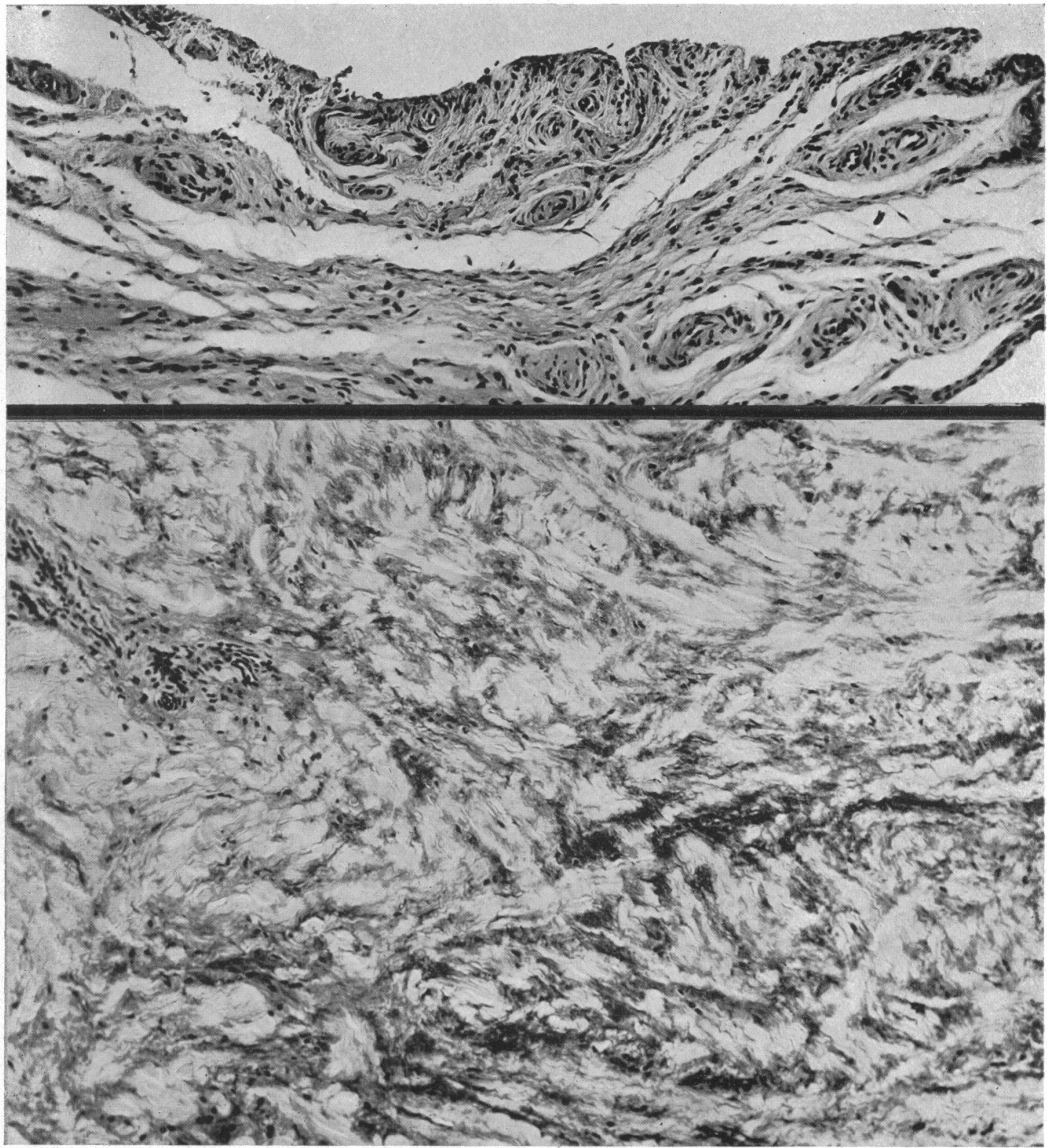

Fig. 12.-Microphotograph $(\times 130)$ of synovial membrane and capsule from 2 nd $M C P$ joint right, showing marked accumulation of basophil ground substance between collagen fibres and normal synovial membrane. Case J.G.

A further case showing what is thought to be a more advanced degree of this is seen in the autopsy series.

Case 25. M.G., f., æt. 45. Four years ago, tonsillitis, followed by pleurisy and rheumatic feverpain in most joints and nodules on elbows and legs - in bed for six months. Five weeks before admission sore throat, pain in limbs worse, affecting hands, shoulders, and knees; some dyspnœa on effort and œdema of feet. On examination ulnar deviation and swelling $M C P$ joints right hand. Tenderness and slight limitation of thumbs. Very slight limitation of shoulders by pain. Heart showed mitral systolic and later diastolic murmurs. X-ray shows subluxation and hook erosions of the $M C P$ heads (Fig. 17). Fever $\left(101 \cdot 5^{\circ}\right)$. 


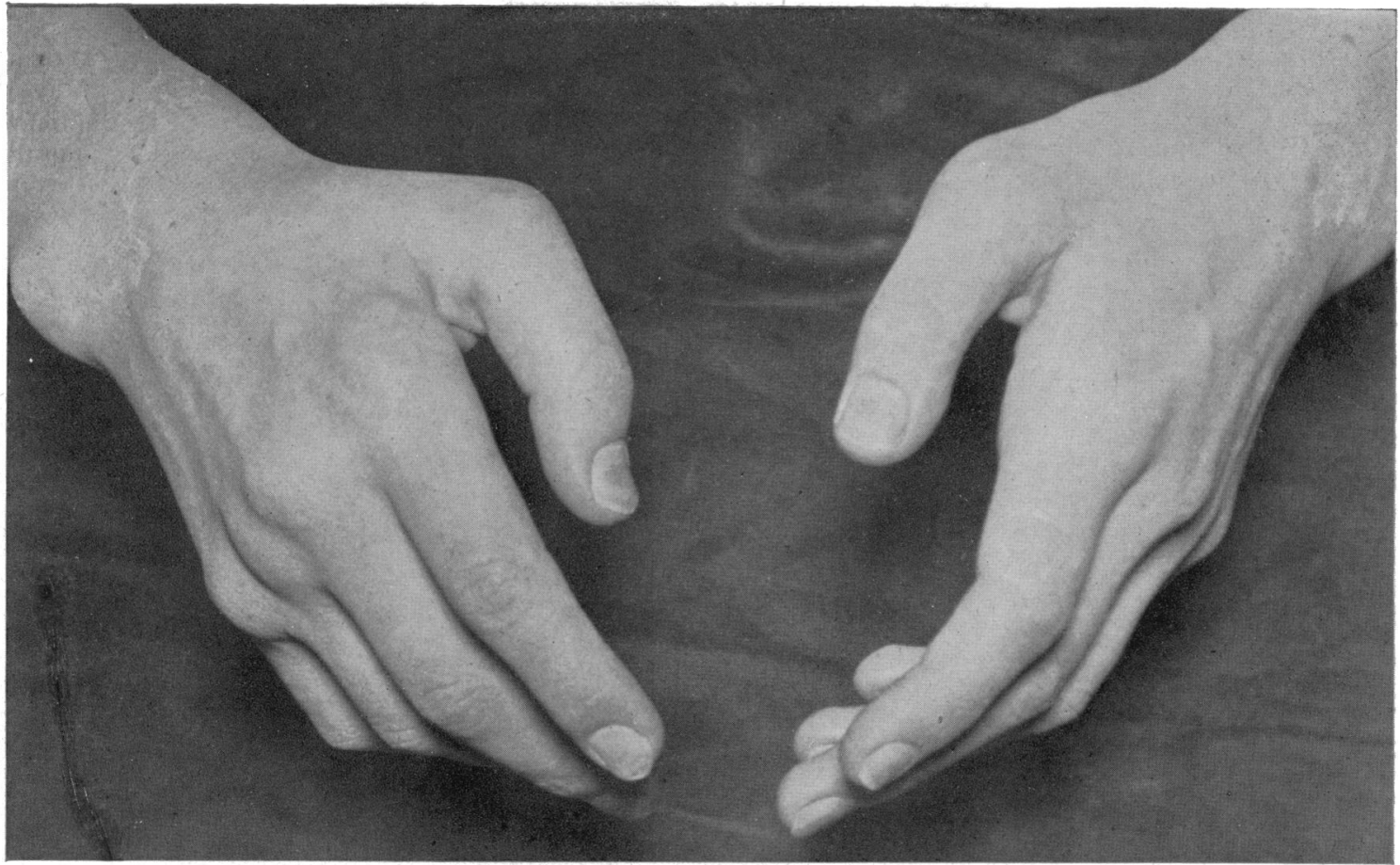

Fig. 13.-Hands showing palmar contracture. $M C P$ flexion, and soft tissue swelling. Case O.L.

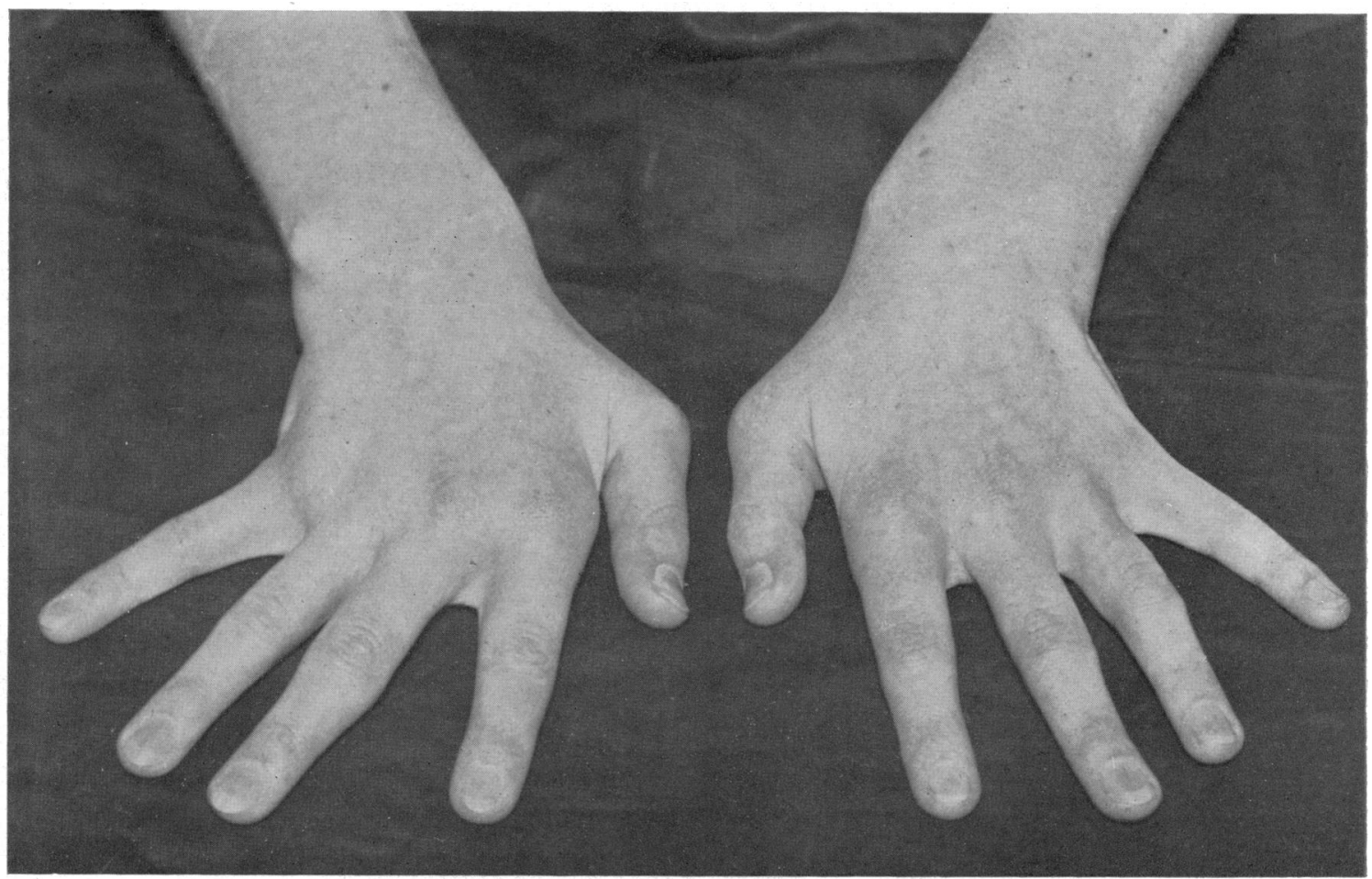

FIG. 14.-Hands showing ulnar deviation correctable voluntarily. Case O.L. 

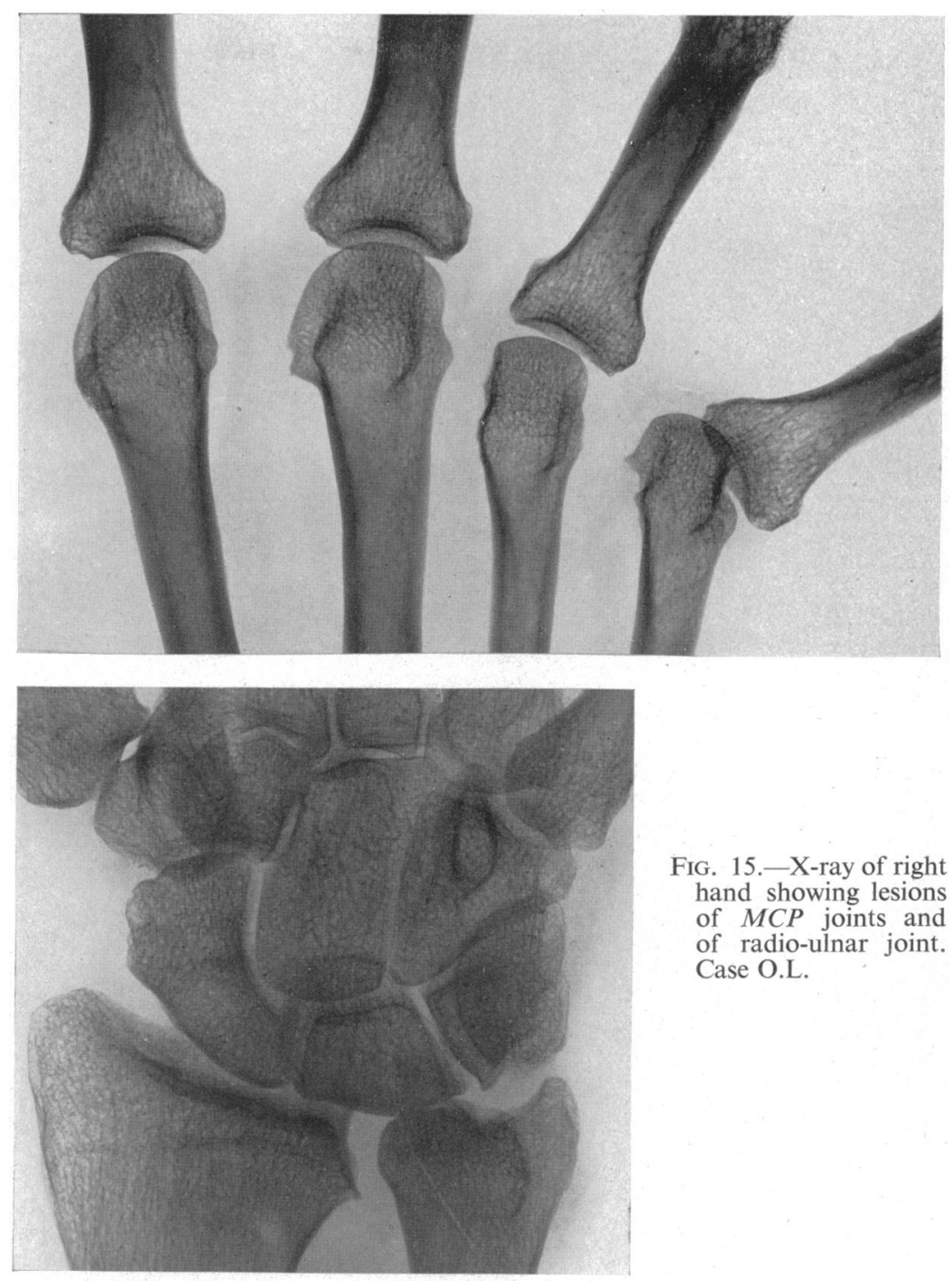

FIG. 15.-X-ray of right hand showing lesions of $M C P$ joints and of radio-ulnar joint. Case O.L.

B.S.R. $112 \mathrm{~mm}$./hr. Group A hæmolytic streptococci isolated from throat. She died of sudden heart failure one month after admission.

Necropsy showed pericarditis, chronic mitral stenosis, acute mitral and aortic endocarditis with many large Aschoff nodules. No joint sections taken.

These X-ray changes are very similar to those seen in the preceding case but represent a more advanced and a more burnt-out aspect.

Lastly, two other cases from the autopsy series are detailed.

Case 26. A.T., f., æt. 70. Rheumatic fever æt. 7, 17, and 47 years and rheumatoid arthritis " for years: occasional pain and disability in joints for many years." On examination systolic and diastolic murmurs were heard at apex; auricular fibrillation was also noted.

Necropsy. Externally rheumatoid arthritis of hands (no further examination of joints). The heart was enlarged and showed thickening of the tricuspid valves; mitral and aortic stenosis; and terminal verrucous endocarditis. The pericardium was healthy, the myocardium showed fibrosis but no recent activity. Carcinoma of cæcum. 
FIG. 16.-Microphotograph $(\times 175)$ showing normal synovial membrane and fibrosis of connective tissue between collagen bundles with some nuclear fragmentation. Case O.L.

As neither X-rays nor section of joints were available, it is impossible to decide on the exact status.

Case 27. A.W., f., was first admitted to Hammersmith Hospital in July 1935 complaining of tinnitus, vertigo, and palpitation. She was then 59 years of age, and gave a history of good health all her life, her only illness being scarlet fever 30 years previously, with rheumatism. The notes specify that she had not had rheumatic fever. Examination at the time showed the presence of a soft apical systolic murmur at the apex, the apex beat was thought to be $12 \mathrm{~cm}$. from midline; B.P. 150/84. X-ray showed enlargement of left ventricle and unfolding of the aorta.

Second admission in March 1936, under Dr. Wood, for functional dyspepsia. Heart sounds normal with no adventitious sounds. Attended for one year.

She was next seen in June 1943 complaining of pain in muscles of left arm. Some tenderness was noted 


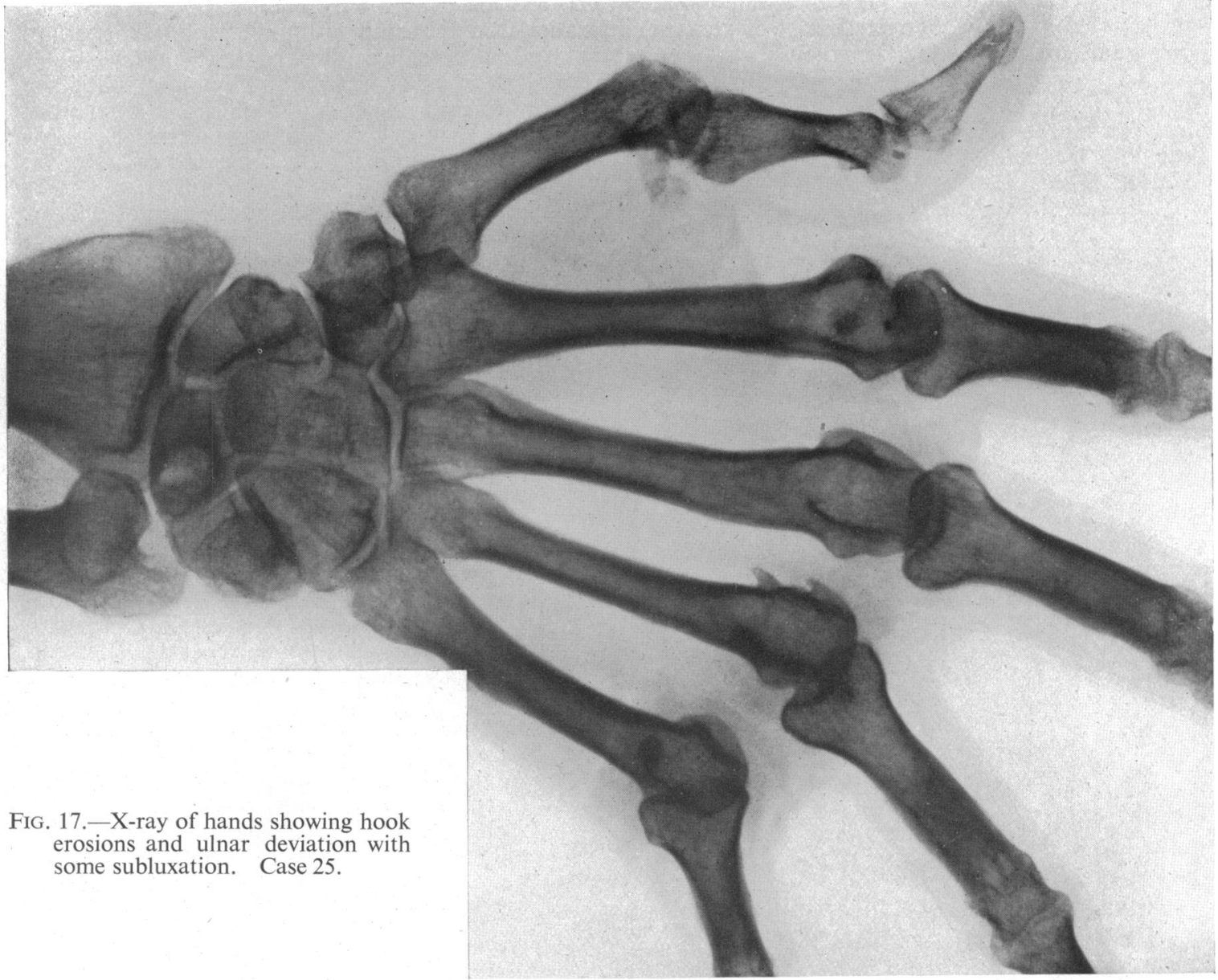

there and in left buttock; a systolic murmur was heard in the heart. No ankle œdema. Temperature $99 \cdot 4^{\circ} \mathrm{F}$. A month later, pain in the shoulders and other joints shifting about, worse in the mornings. She was thought at that time to have rheumatoid arthritis or heart disease. Heart and lungs were recorded as normal. There was pain on movement of the joints but no limitation. B.S.R. $14 \mathrm{~mm}$./hr. Westergren. She was treated with radiant heat and exercises, and from October 1943 was confined to bed for 7 weeks with a generalized acute rheumatoid arthritis. Temperature, $100^{\circ} \mathrm{F}$. for a week or so.

In July 1944 she was readmitted (Professor McMichael) complaining of dyspnœa on exertion developing gradually over the past two years and swelling of the legs in the evening. For the previous six months she had had stiffness, pain and swelling of her hands and later of her ankles and knees. Physical examination revealed the presence of mitral stenosis: a blowing systolic and a rumbling diastolic murmur at the apex and a systolic at the base. B.P. 145/75. Her joints were thought to be characteristic of rheumatoid arthritis with ulnar deviation of both hands; right more than left. The PIP joints were swollen and the grip was weak. There was œdema and stiffness of ankles: slight swelling of knees but no fluid. She was afebrile at the time. B.S.R. $65 \mathrm{~mm}$./hr. Hæmoglobin 11.6 g. R.B.C. 4,600,000. The joints were not X-rayed.

She was admitted for the fourth and last time in 1948. Up to two days before admission she had been able to walk about and managed a few stairs. She then developed palpitations and pain in the chest.

On examination there was auricular fibrillation and a systolic murmur in all areas. B.P. 150/70. Edema of ankles and sacrum, enlargement of liver and albuminuria. There was gross ulnar deviation with dinnerfork deformity of the fingers and fibrous ankylosis of the fingers (E.G.L.B.). There were no nodules and no other joints actively involved. X-rays showed peculiar well-defined hook-erosions of the $M C P$ heads, with a considerable amount of dislocation: wrist-joint changes with periostitis and erosions of the metatarsal heads (Fig. 18). 
Investigations showed continued albuminuria, low plasma proteins $(3 \cdot 4-4 \cdot 1 \mathrm{~g} . / 100 \mathrm{ml}$.) and a low œdema protein $(750 \mathrm{mg}$.). Congo red showed 65 per cent elimination from the serum in 1 hour. B.S.R. $15 \mathrm{~mm} . / \mathrm{hr}$. Her condition remained stationary until 4 days before death when congestive failure became worse.

Necropsy showed rheumatic heart disease with partial obliteration of pericardium by loose adhesions; dilation and hypertrophy of both auricles. Mitral valve admitting one finger only, with shortened chordæ, a thickened shelf-like band and many vegetations $0.5-1.0 \mathrm{~mm}$. in diameter along the contact margin. Tricuspid aortic and pulmonary valves were normal. There was some coronary atheroma and calcification. Heart $390 \mathrm{~g}$.

Sections show some perivascular fibrosis consistent with healed Aschoff's lesions but no sign of activity.

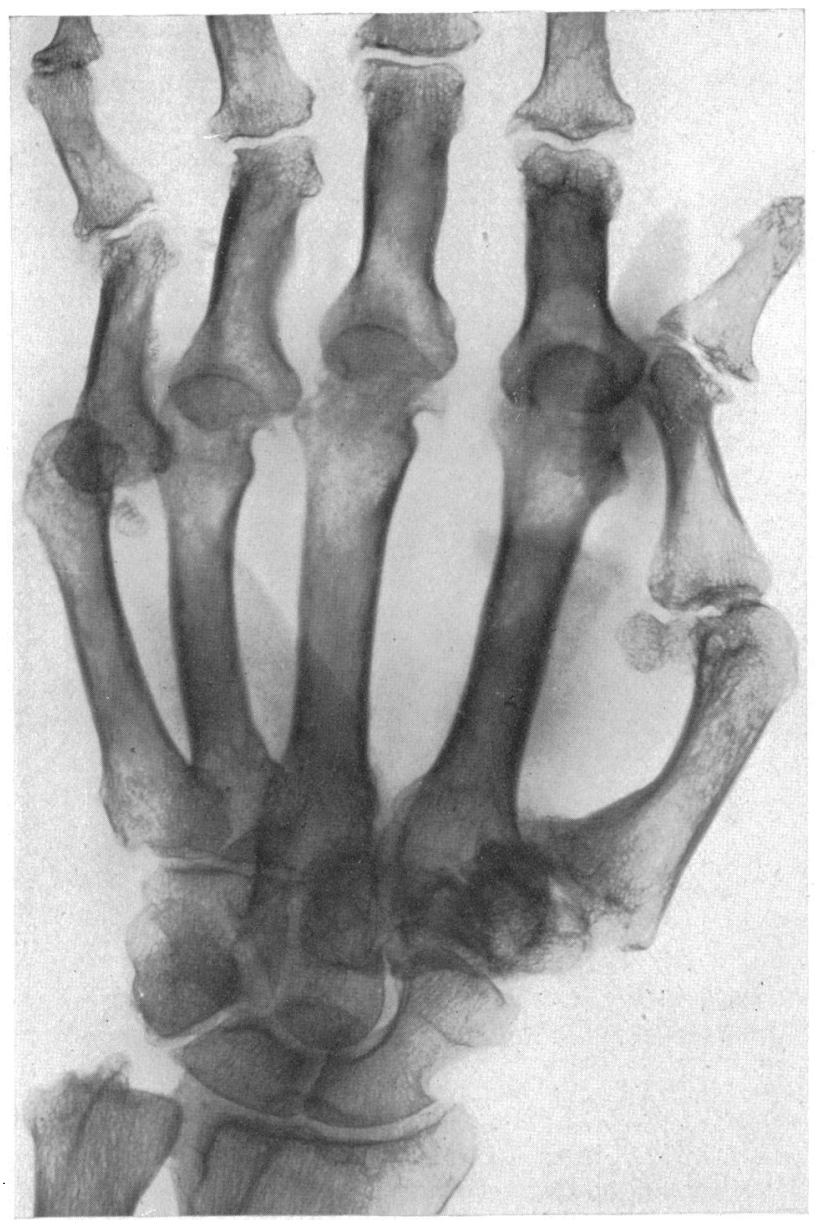

The valve showed fibrosis and vascularity but no active valvulitis, the vegetations being terminal thrombotic ones. The knee joint showed fibrillation of the cartilage and some destruction of the internal meniscus. Our opinion on the gross specimen was that this was degenerative joint disease. Sections of synovial membrane therefrom showed a few lymphocyte collections, a few plasma cells and pigment-containing macrophages consistent with a relatively inactive and healed inflammatory lesion. There was no pannus formation. Sections of the right index PIP joint showed destruction of cartilage at several points with replacement by fibrous tissue together with a marked decrease in joint space due to encroachment by the synovial membrane up to the margin of cartilage (Fig. 19). Active inflammatory synovitis was absent although a few round cells and plasma cells were visible. There were in addition organizing and packed pulmonary emboli, from thrombosis of femoral and iliac veins, together with amyloid disease affecting especially the kidneys.

The joint lesions in this case represent either healed and inactive rheumatoid arthritis or a severe degree of chronic fibrous rheumatism, following rheumatic fever. In favour of the latter are the peculiar hook erosions (as in Case 15) and the deformity which is the same as Jaccoud originally described. These two cases are sufficient to make one examine very carefully any similar case coming along, since if we had been able to examine sections of clinically affected joints we should probably be able to speak with more certainty. Bennett (1943) mentions briefly a very similar case presenting a clinical picture that was difficult to distinguish from mild rheumatoid arthritis.

"She was a woman of 45 years of age who had been told that she had rheumatic fever and rheumatic heart disease five years before her last hospital admission. She then complained periodically of pain and stiffness hyper-extension of proximal interphalangeal joints and flexion, with subluxation, of $M C P$ joints. Note hook erosions. Case 27. 
in most of her joints during the previous five years. On several occasions tenderness, swelling, and limitation of motion were elicited in the digital joints. Post-mortem, typical valvular, myocardial and pericardial lesions of rheumatic heart disease. Examination of the spine, knees, metatarsophalangeal and interphalangeal joints of the most severely affected toes and the metacarpophalangeal and interphalangeal joints of one affected finger revealed a mild diffuse lymphocytic, plasma cells and mononuclear leukocytic infiltration in the synovial and subsynovial tissues. All other articular structures were negative."

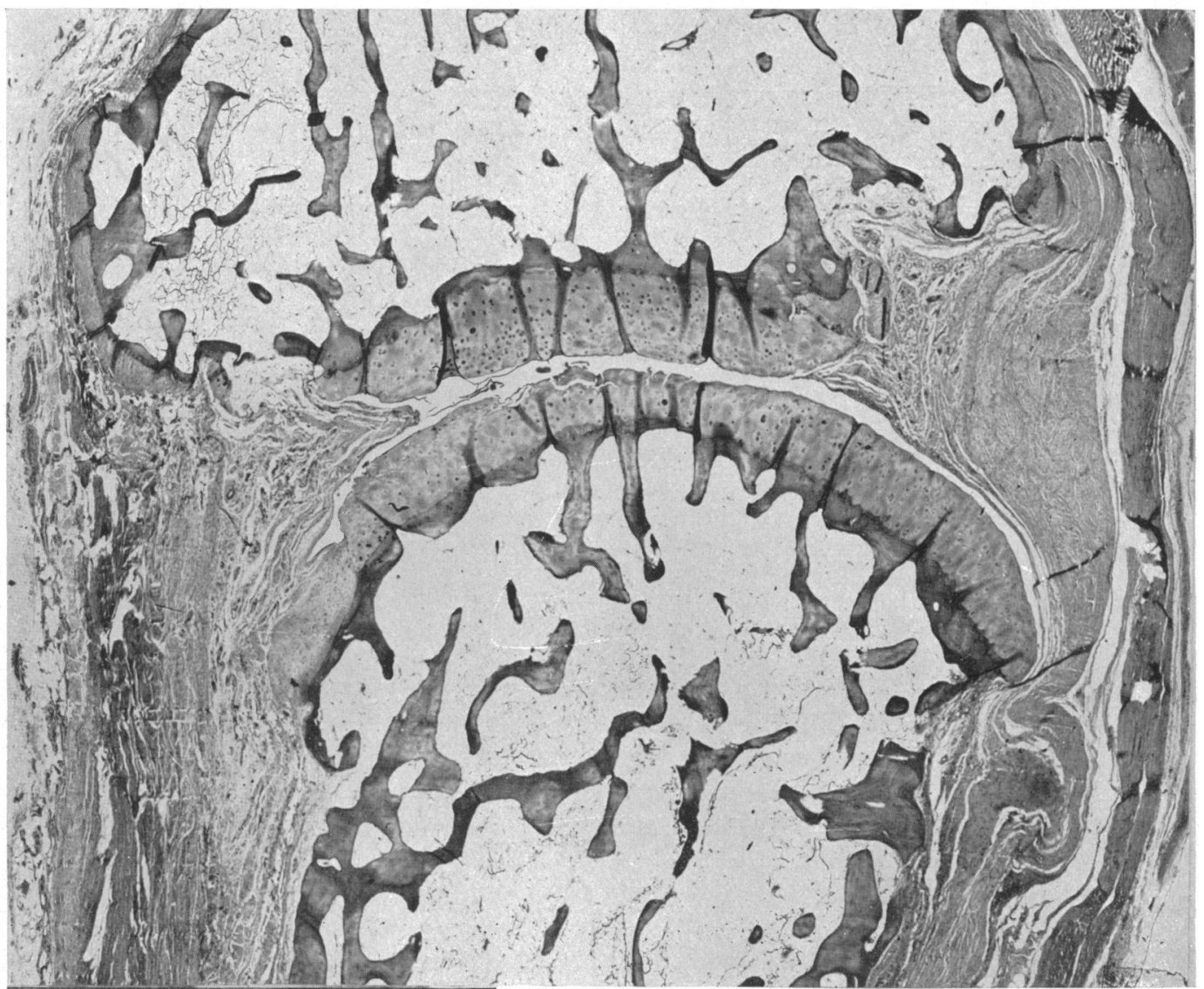

FIG. 19.-Microphotograph, sagittal section of proximal interphalangeal right index showing inactive joint lesion with destruction of cartilage, together with X-ray of same. Magnification, $\times 17$. Case 27 .

He concluded that, in the absence of ætiological evidence to the contrary, it would seem advisable to continue to look upon rheumatic fever and rheumatoid arthritis as separate and distinct entities.

A few cases have been described besides those previously cited by Garrod, Symes, and Bach, that may fit into this category. Careful and detailed clinical accounts in the classical French tradition have been published of a "rheumatisme dislocant" following rheumatic fever, first by Lereboullet and Moujon in 1920 and then by others (Table V). These four cases closely resemble each other: following several attacks of rheumatic fever, residual deformity develops consisting of ulnar deviation and subluxation at the $M C P$ joints. This is passively correctable and the ligaments are lax. 
Crepitus may be felt. It is most marked in the right hand and in the fourth and fifth fingers, but may affect the feet. There is no functional disability, and the B.S.R. may be normal or raised. $\mathrm{X}$-ray may show no bony abnormality or there may be minor lesions of the carpal bones and of the metacarpal heads. It is said to be distinguished from Jaccoud's type by the presence of laxity rather than fibrous contraction, but it seems to the present author that "rhumatisme dislocant" and Jaccoud's fibrous rheumatism represent the same complication of rheumatic fever.

TABLE V

\begin{tabular}{|c|c|c|c|c|c|}
\hline Author & $\begin{array}{l}\text { Age and } \\
\text { sex }\end{array}$ & $\begin{array}{l}\text { Age at onset } \\
\text { of R.F. }\end{array}$ & $\begin{array}{l}\text { No. of } \\
\text { attacks of } \\
\text { R.F. }\end{array}$ & $\begin{array}{c}\text { Age at onset } \\
\text { of joint }\end{array}$ & Heart lesion \\
\hline $\begin{array}{l}\text { Lereboullet and Moujon } \\
\text { Boidin, Vallery-Radot and Roux }\end{array}$ & $\begin{array}{ll}\text { F. } & 26 \\
\text { F. } & 51\end{array}$ & $\begin{array}{r}13 \\
8\end{array}$ & $\begin{array}{l}4 \\
3\end{array}$ & $\begin{array}{l}20 \\
31\end{array}$ & $\begin{array}{l}\text { Mitral lesion. } \\
\text { Mitral lesion. } \\
\text { Failure fibrillation }\end{array}$ \\
\hline Boidin and Droguet & F. 72 & 13 & 3 & 30 & $\begin{array}{l}\text { Mitral lesion. } \\
\text { Failure, fibrillation. }\end{array}$ \\
\hline Arlet and Dunglas & F. 42 & 12 & 3 & 27 & Mitral lesion. \\
\hline
\end{tabular}

Still, in his original paper " on a form of chronic joint disease in children" described an "extremely rare" form of which he had seen only one case, a boy, aged 5, whose fingers had become stiff from the formation of fibrous nodules over the tendons at the age of $31 / 2$ years. Limitation and swelling of the elbows and wrists followed. "There was no evident affection of the phalangeal joints although there was marked limitation of movement, the terminal phalanges being flexed and some of the proximal phalanges hyper-extended." There was a loud apical systolic bruit and subcutaneous fibrous nodules on finger, elbow, and hip. " In this particular case although there was no history of acute rheumatism, the association of a cardiac bruit with fibrous nodules was, I think, sufficient proof of the rheumatic nature of the joint affection. There can be no doubt that it is identical with the disease described by Jaccoud as chronic fibrous rheumatism." Many others have also invoked Jaccoud's name but with less authority for doing so. It is widely held that Brigidi and Banti have published a necropsy on such a case (1880); in fact there was no valvular disease of the heart at all in their patient.

A case more comparable to that of Jaccoud's was described by Worster-Drought (1930). A woman, aged 27 , had suffered attacks of rheumatic fever at the ages of $12,14,17,18$, and 22, after which she developed severe ulnar deviation with periarticular swelling but no limitation. She had rheumatic heart disease. Young and MacMahon (1935) describe 2 patients in detail and list a further 8 with atrophic arthritis and mitral stenosis. Their first patient, after an attack of acute rheumatic fever, aged 15, developed two years later a deformity in the hands and feet. At the age of 18 her deformities were the same as they were seen to be on examination at the age of 37 , suggesting that the lesions had healed within 3 years of the onset of acute rheumatic fever. The heart was in congestive failure with stenosis and fibrillation. The joints showed flexion with lack of complete extension in the $M C P$ joints, ulnar deviation and osteoporosis. Other cases were not detailed so fully.

I had seen up to 1948 one such patient, a woman under the care of Dr. Bauer at the Massachussetts General Hospital, Boston, in 1937, in whom there was little radiological change or joint symptoms: correctable ulnar deviation and periarticular swelling of the $M C P$ joints of both hands gradually developed following repeated attacks of rheumatic fever with residual heart involvement.

\section{Discussion}

It is hoped that this account will stimulate a re-inquiry into the existence of chronic secondary polyarthritis, as the French and Germans call the chronic joint change following rheumatic fever. 
We believe that this is a real entity distinct from rheumatoid arthritis and that we have demonstrated it, at least in one case (O.L.). It is, however, we think, exceedingly rare, at least in this advanced form with bone destruction, and we find it difficult to believe that Kahlmeter's figures for incidence obtain in this country. Kahlmeter investigated the electrocardiographic evidence of myocarditis and the clinical presence of valvular lesions in a group of polyarthritis, 37 of whom were of secondary type, i.e. following and related to an earlier attack of rheumatic fever and 48 of whom were of primary type. His criteria were a prolongation of $P-R$ interval to 0.20 or more, QRS changes, or inversion of T I. He compared this group with a control group of 65 acute rheumatic fever cases, 106 sub-acute, 68 non-rheumatic infections, 72 healthy people, and 45 non-cardiac patients, excluding all cases over 50 years, or with a nephritis, syphilis, or blood pressure above $160 \mathrm{~mm}$., and in the group with chronic primary polyarthritis, all with previous rheumatic fever. It might be concluded from his figures that chronic secondary polyarthritis as a distinct entity closely allied to rheumatic fever is almost as common as primary chronic polyarthritis (i.e. rheumatoid arthritis).

It is possible that this is so, and that the variously higher figures for the incidence of rheumatic heart disease in our own and other autopsy series than in control series of the same age group are not due to selection but reflect a variable proportion of cases of chronic secondary polyarthritis in the various series. If this is really so (and we have no grounds for believing it), it should be possible to distinguish clinically, radiologically, and pathologically between the two types, on grounds other than those of Kahlmeter (presence of valve lesions and electrocardiographic abnormalities). Can we reconstruct a tentative picture of the syndrome that we must keep a look out for? From our own one probable and three more possible cases that we have cited in this category, the following features that might prove to differentiate it from rheumatoid arthritis proper are:

(a) There is a history of acute rheumatic fever attacks, usually multiple and distinguishable historically from acute rheumatoid only by the migratory nature of the initial polyarthritis, perhaps the character of the rash, the presence of chorea, the development of heart lesions, or the response to salicylates. Nodules have occurred.

(b) Recovery has been delayed and associated with stiffness of the $M C P$ joints, but this may pass off or the patient may gradually slide into a state of joint deformity.

(c) The characteristic deformity is due to periarticular and fascial fibrosis rather than synovitis.

(d) It consists of flexion at the $M C P$ joints with some periarticular soft tissue swelling over them and in the wrist region, together with ulnar deviation and/or subluxation affecting particularly the fourth and fifth fingers. This ulnar deviation is correctable by voluntary effort in the early stages. There may furthermore be a hyperextension at the PIP joints, although these are not themselves swollen.

(e) Tendon crepitus may be elicited (and in this connection we could cite cases of rheumatic fever with transient flexor tendon contractures associated with palmar nodules, as a probable preceding phase (e.g. Bywaters, 1949).

$(f)$ The disease is relatively inactive, with a normal sedimentation rate and often little or no complaint of the joints, and in the early stages retention of normal functional capacity.

(g) Radiologically the earliest bone change is erosion of the metacarpal heads on the most palmar and radial part of their circumference in the anteroposterior projection, producing later a hook-like erosion.

The other end of this range of cases also may prove a diagnostic problem. In rheumatoid arthritis with valvular disease and evidence of pericarditis, the possibility of rheumatoid heart disease should be borne in mind, especially if there is a great deal of nodule formation. As this type is apparently so rare, however, the likelihood is that most such individual cases will prove ultimately to have rheumatic heart disease.

There remains the possibility (which we do not favour) that rheumatoid arthritis and rheumatic fever are variants of one disease entity. Both are comparatively common diseases and if this were so between-grades should be frequent: we think that the rare between-grades that are seen are spuri- 
ous and that such cases will be found on fuller and adequate examination to fall clinically and pathologically into one of the several types we have described. However, as so many have commented, until the causes of one or both are known this is an occupation for theorists. In practice we know that rheumatic fever attacks the heart and rheumatoid arthritis the joints; the occurrence of rare combinations such as we have described scarcely affects the practical conduct of the physician but an adequate investigation of them may throw a great deal of light on the nosological status of this group of diseases.

\section{SUMMARY}

On the basis of a necropsy series of 27 cases of rheumatoid arthritis and 4 cases of spondylitis ankylopoietica, the following three types of clinical relationship between rheumatoid arthritis and rheumatic fever are distinguished, besides uncomplicated rheumatoid arthritis alone and those presenting rheumatic heart disease alone.

(1) Rheumatoid arthritis with deformity of valves due to rheumatoid granulomata in the valve cusp and ring, and frequently accompanied by pericarditis. One such case is described and the close resemblance of pericardium and synovial membrane is pointed out.

(2) Rheumatoid arthritis developing in a person who has already had, usually during childhood, an attack of rheumatic fever which has left rheumatic heart disease.

(3) Rheumatic fever.which has occurred several times and has left in its wake a chronic type of rheumatism affecting mainly the metacarpo-phalangeal joints with some pericardial swelling, ulnar deviation, and subluxation. Biopsies in two cases showed capsular fibrosis and normal synovial membrane. In one case, this type of " chronic secondary polyarthritis" had produced bone and cartilage erosions and in another probable case this had commenced to form characteristic hook-like deformity of the metacarpo-phalangeal heads. It is thought that it might be possible to distinguish these cases from more ordinary rheumatoid arthritis with coincident rheumatic heart disease on clinical grounds. A review of the subject is given and a history of the clinical confusion traced from the time of Jaccoud who first recorded this chronic type of post-rheumatic joint disease and left a clinical description as good as any subsequent account of the disease.

I am most grateful to my colleagues in the Departments of Medicine and Pathology at the Postgraduate Medical School of London and in the Canadian Red Cross Memorial Hospital, Taplow, for allowing me to see and cite their cases together with the pathological records and material. I am indebted also to Dr. Coghill who allowed me to see Case O.L., and to Dr. Francis Bach who furnished Figure 3. Mr. Wilmott took the microphotographs.

\section{REFERENCES}

Arlet, J., and Dunglas, J. (1949). Rev. du Rhumatisme, 16, 230.

Bach, F. (1935). The Rheumatic Diseases, Cassell, London.

Baillie, Matthew (1797). Morbid Anatomy, 2nd ed. Johnson, London.

Barjon, F. (1897). Thésè de Lyon.

Bagenstoss, A. H., and Rosenberg, E. F. (1941). Arch. intern. Med., 67, 241.

Barahona, R., and Gorena, M. (1947). Prensa med. argent., 34, 2363.

Bayles, T. B. (1943). Amer. J. med. Sci., 205, 42.

and McGinn, S. (1943). Unpub. observation cited by Bayles.

Bennett, G. A. (1943). Arch. intern. Med., 19, 111.

Boidin, L., and Droguet, - (1941). Bull. mem. Soc. Hôp., Paris, 56, 9.

- Vallery-Radot, P., and Roux, M. (1938). Ibid., 54, 345.

Bouillaud, J. (1836). Nouvelle Researches, Paris.

Brigidi, V., and Banti, G. (1880). La Experimentale, 1, 281.

Bywaters, E. G. L. (1948). Clin. Sci., 6, 281. (1949). Ann. Rheum. Dis., 8, 1.

Charcot, J. M. (1891). Clinical lectures on senile and chronic diseases, translated by W. S. Tuke. New Sydenham Soc., Vol. 95.

Clark, W. S., and Bauer, W. (1948). Ann. Rheum. Dis., 7, 39.

Dawson, M. H. (1935). Med., 5, 605.

and Tyson, T. L. (1936). J. Lab. Clin. Med., 21, 575. 
Edstrom, G. (1935). Febris Rheumatica, Lund.

Ellman, P. (1944). Lancet, 2, 581.

Feiring, W. (1945). N.Y. State J. Med., 45, 1855.

Fingerman, D., and Andrus, F. C. (1943). Ann. Rheum. Dis., 3, 168.

Fischer, A. (1933). Rheumatismus u. Grenzegebiete. Springer, Berlin.

Fischmann, E. J., and Gwynne, F. J. (1943). Brit. Heart J., 10, 125.

Freund, E. (1929). Gelenkerkrangungen. Urban \& Schwarzenberg, Wien.

Garrod, A. B. (1876). Nature and Treatment of Gout and Rheumatic Gout. 3rd ed., London.

Garrod, A. E. (1890). Treatise on Rheumatism and Rheumatoid Arthritis. London

Gruenwald, P. (1948). Arch. Path., 46, 59.

Grzimek, N. (1932). Virchows Arch., 286, 286.

Hall, E. M., and Anderson, L. R. (1943). Amer. Heart J., 25, 64.

Hench, P. S., and Rosenberg, E. F. (1941). Proc. Mayo Clinic, 16, 808.

Homolle, G. (1882). Nouveau Dictionaire de Medicine et de Chirurgie Pratique, Vol. 31, Edit. S. Jaccoud, Paris.

Hultgren, H. N. (1948). Arch. Path., 45, 694.

Jaccoud, F. S. (1869). Lecons de Clinique Medicale a l'Hop. de la Charite. 2nd ed. Paris.

Kahlmeter, G. (1934). Acta Med. Scand., Supp. 59, 611

Karsner, H. T., and Koletsky, S. (1940). Trans. Assoc. Amer. Phys., 55, 188.

Kast, L. (1901). Prag. med. Wchnschr. 26, 493, 508, 521 (cit. Bagenstoss and Rosenberg).

Keil, H. (1936). Bull. Instit. Hist. Med., 4, 789.

Klinge, F. (1933). Ergebn. allg. Path. path. Anat., 27, 154.

Lereboullet, P., and Moujon, J. (1920). Bull. mem. Soc. Hôp., Paris, 44, 86.

Lucchesi, O., Lucchessi, M., and de Melo, H. K. (1947). Hospital, Rio de Jan., 32, 699.

MacMichael, W. (1932). The Gold-headed Cane, New York.

Pribram, A. (1902). In Nothnagel Specielle Path. u. Therapie, Holder, Wien 1902, 7, Part 5.

Rantz, L. A., Boisvert, P. J., and Spink, W. W. (1947). Arch. intern. Med., 79, 401.

Raven, R. W., Weber, F. P., and Price, L. W. (1948). Ann. Rheum. Dis., 7, 63.

Rogen, A. S. (1947). Brit. med. J., I, 87.

Rosenberg, E. F., Hench, P. S., Bishop, L. F., and Weintraub, H. J. Cit. Rosenberg in Comroe Arthritis. 3rd ed. Lea and Fibiger, Philadelphia.

Smythe, C. J. (1943). Discussion on Rosenberg, Bagenstoss and Hench. Ann. intern. Med., $19,114$.

Spender, J. K. (1889). Lancet, 2, 947.

Still, G. F. (1897). Med-chir. Trans., 80, 47.

Symes, J. O. (1905). Rheumatic Diseases. Lane, London.

Wells, W. C. (1812). Trans. Soc. Improv. Med. and Chir. Knowledge, 3, 373.

Wetherby, M. (1932). Ann. intern. Med., 50, 926.

Worster-Drought, C. (1930). Proc. Roy. Soc. Med., 23, 948.

Young, A. G., and MacMahon, H. E. (1935). J. Bone and Joint Surg., 17, 151.

Young, D., and Schwedel, J. B. (1944). Amer. Heart J., 28, 1. 